\title{
A Study on Improving of Incubating-Efficiency of Incubators in Zhejiang Province, China
}

\author{
Zhenfeng Ge* \\ National Institute of Development Administration (NIDA), Bangkok, Thailand \\ Email: dr.kevinge@gmail.com
}

How to cite this paper: Ge, Z.F. (2018) A Study on Improving of Incubating-Efficiency of Incubators in Zhejiang Province, China. iBusiness, 10, 144-176.

https://doi.org/10.4236/ib.2018.103009

Received: August 27, 2018

Accepted: September 25, 2018

Published: September 28, 2018

Copyright $\odot 2018$ by author and Scientific Research Publishing Inc. This work is licensed under the Creative Commons Attribution International License (CC BY 4.0).

http://creativecommons.org/licenses/by/4.0/

\begin{abstract}
The incubator's promotion of entrepreneurial development and the help of N.E. growth make its research have a strong practical significance. At the same time, concern for the sustainability of incubator development, the core of the problem lies in the ability to configure their incubator resources, that is, the level of incubating-efficiency. By DEA, HAC, In-depth interviews to discuss the situation in Zhejiang Province incubators, as well as influencing factors on incubating-efficiency and the improving path of the sample derived from the incubator in Zhejiang Province, which proposed a new hierarchical model and incubation Strategies for improving of incubating-efficiency.
\end{abstract}

\section{Keywords}

DEA, Incubating-Efficiency, Business Incubator

\section{Introduction}

In the late 1980s, under the impetus of UNDP \& UNFSTD ${ }^{1}$, the incubator came to China and received the attention and support of the government. In 1987, "Wuhan east lake new technology entrepreneurship service center", the first incubator in China, was established, and the industrial development of the incubator in China was also started. At present, the incubator has become a platform for public policy tools and commercial resources. With the policy of mass entrepreneurship and innovation, by 2017, the number of incubation platforms in China has been ranked first in the world, and 2006-2017 Business Incubator Quantity Change in China as shown in Figure $1^{2}$. In order to better adapt to the ORCID ID: 0000-0002-9318-0877.

'UNDP \& UNFSTD: The United Nations Development Programmer and United Nations Fund of S \& T Development.

${ }^{2}$ Data source from China Entrepreneurship incubation development report 2018, which is published by Scientific and technical documentation press, is the National Innovation Survey System Series Report. 
needs of China's entrepreneurial activities in the next stage, China's existing incubators will face the pressure of improving the incubating-efficiency and adjusting the organizational structure, and the elimination and merger are inevitable. How to achieve sustainable incubation, in the background of marketable operations, is a major challenge to the current incubation operation.

\subsection{Research Questions}

1) There are some points that guided this research.

- Factors influencing entrepreneurial behavior and resource factors for new enterprise development;

- The resource allocation efficiency of the influencing factors and improving path;

- The new incubation system to improve the efficiency of incubator.

2) The research significance

From the perspective of incubator operation, this paper will provide a new research direction for the construction of efficient incubation mode and a new theoretical direction for the development of the next generation of incubators through the analysis of the internal and external environmental factors of the incubator and the calculation of the efficiency of the incubator. It is a supplement and perfection to the existing research theory of incubator.

In addition, since entering the 21st century, the hot rush of starting business around the world, the number and speed of new enterprises go beyond any period of history. In this round of entrepreneurial growth, incubators create a significant number of new jobs. According to the OECD member states in the 2012-2016 social employment survey [1], each member of the new enterprise (employee number less than 9 people) showed considerable achievements, top three, respectively is South Korea, the United States, Turkey, such as Figure 2. The incubation of the incubator as a service provider to integrate social resources, to channel entrepreneurship, to promote innovation, to incubate a new enterprise, is the most concentrated service platform for entrepreneurial resources, and also a core infrastructure of regional or national innovation and new enterprise incubation. Therefore, it is of practical significance to study the efficiency of a regional incubator in resource integration and the incubating-efficiency. There is a strong market demand for exploring the new generation of efficient incubators and the efficient delivery of incubation element.

\subsection{Research Objective}

In this paper, sample area for China's Zhejiang province; The data refer to the 2017 China torch statistical yearbook. By analyzing the incubation mechanism of the incubator and calculating the incubation efficiency, a new model of efficient incubation system was constructed to improve the efficiency of the existing incubator. At the same time, the strategy of incubating-efficiency optimization was presented. 


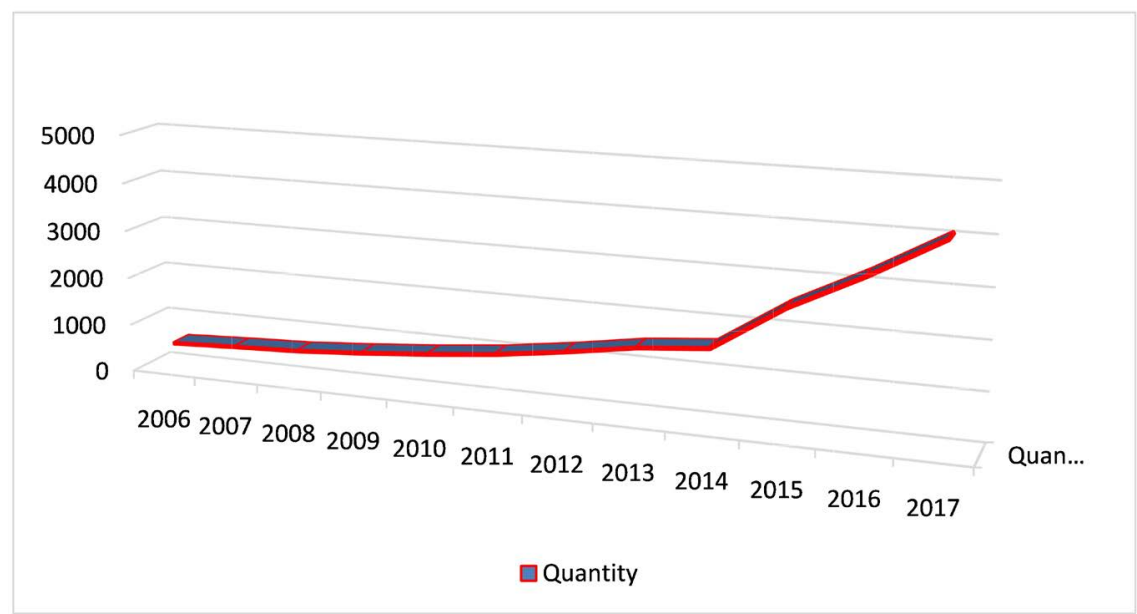

Figure 1. 2006-2017 China business incubator quantity change chart.

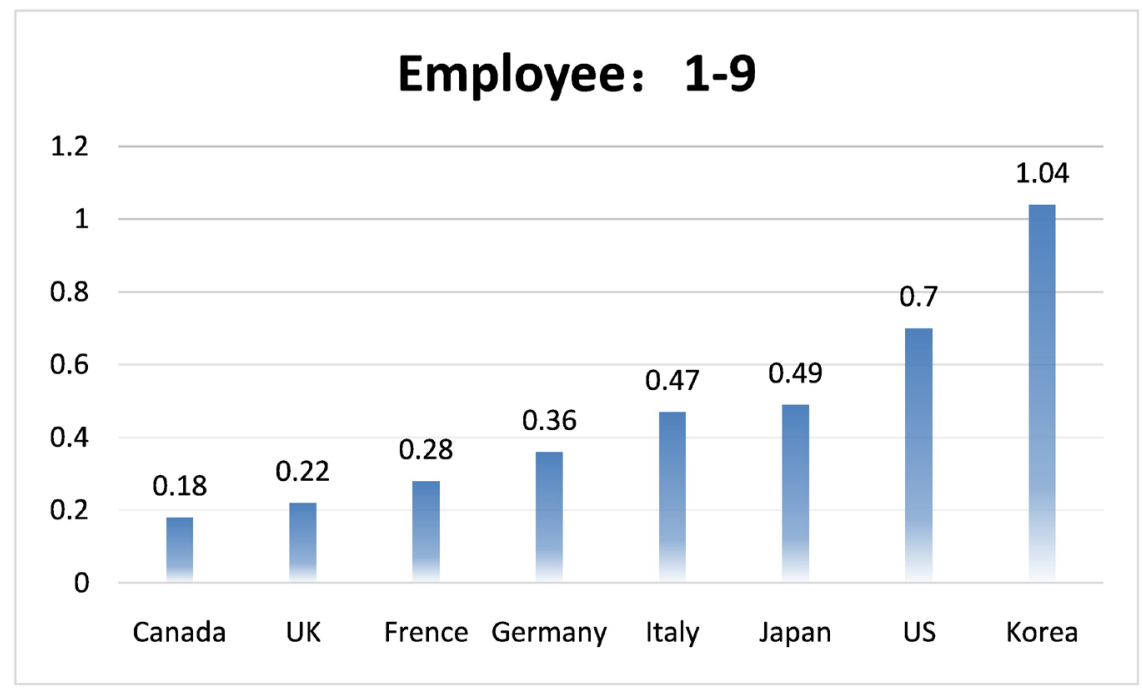

Figure 2. The employees of N.E. of OECD members.

\section{Literature Review}

\subsection{The Research Related-Concept of Incubator}

From the current research, scholars have made different definitions and understandings of common concepts such as entrepreneur, new enterprise and incubator based on their own research needs. Therefore, in order to avoid the risk of ambiguity in the presentation of the study, this paper hereby reidentifies the concepts involved in this study.

1) Incubator

Incubator, often referred to as for entrepreneurs to provide a wide range of business value-added services facilities, public service institutions; In many cases, the government also acts as a policy tool to stimulate regional economic development. Some scholars believe that "business incubator is a controlled environment designed to cultivate new enterprises". But up to now, there is no consensus on the concept of incubator. In the actual research, it is not difficult to 
find that such kind of incubation platform or organization is also diversified. "innovation center", "science and technology business incubator", "high-tech transform center", "University of Science and Technology Parks" etc. belong to the incubator field [2] [3].

In addition, as a professional manager team, the efficient application of incubation resources is the prerequisite for the improvement of incubation efficien$c y$, and the ownership of the incubator does not have a direct impact on the level of incubating-efficiency.

H1: The incubation efficiency is related to the funding source and ownership of the incubator.

From the development of the incubator, it has a single incubation of individual incubation to the incubation of the network; From focusing on the services and products of individual incubators to studying the process of improving incubation efficiency. With the intensification of market competition in China's incubator industry, the common features of the development of this incubator are increasingly obvious. The management of the incubator has focused on improving the incubation efficiency of N.E. and tried to form an effective incubation resource network through the combination of the incubators.

H2: Hierarchical incubation resources and incubator network connection degree has a positive effect on incubating-efficiency.

2) New Enterprise (N.E.)

There are many names for the for-profit organization that entrepreneurs run, and scholars or institutions don't have a standard term for it. In order to make the concept of incubating enterprises not ambiguous and confusing in the study, this study identified the new-born profit organization established by Entrepreneurs in the incubator as start-ups, and called New Enterprise, or N.E. for short.

\subsection{The Oretical Basis}

1) The Synergetic theory

As the carrier for the incubation resources, a network of resources around the N.E. will be finally formed through the linking of all kinds of incubation resources. According to system theory, the resource network of this incubator is essentially a dynamic cooperative network system, which can be regarded as an integrated incubator system. In this system, the related resource provider will take the incubator as the key core of the incubator system. The system is independent, cooperative, competitive and cooperative. All units in the system jointly affect the quality and efficiency of the incubation of new enterprises in the system. Synergy is one of the main functions of incubator, coordination ability strong and the weak is the basis for efficient configuration of incubation resources.

The synergy of the incubation process for the incubation process has a positive impact on the incubation efficiency.

2) Enterprise life cycle theory 
Enterprise life cycle theory is one of the most classic fundamental theories in management, which has been widely used in all kinds of business research. In the research on the N.E. cultivation and incubating-efficiency improvement, scholars all agree that the development cycle of new enterprises exists. Therefore, more and more scholars apply the life cycle theory to the research of incubator management and new enterprise development. Huang Manhui et al. pointed out that life cycle theory has been one of the basic theories of incubator research when studying Chinese incubator [4] [5]. From the application of life cycle theory in incubator research, only by fully grasping the development law of N.E. and rationally matching the incubation resources of each stage of N.E. can the efficiency of incubation be effectively improved. In addition, a correct understanding of the life cycle of a N.E. is conducive to the understanding and definition of the incubation cycle.

The incubator's ability to locate the N.E.'s life cycle will have a positive impact on the incubation efficiency.

\subsection{Review of Incubation \& Incubation-Efficiency}

1) Efficiency and Incubation

The research of incubation efficiency is not only the core problem in modern enterprise management, but also the basic problem in the field of incubator research. From the application of many efficiency related theories, pare to-efficiency and X-efficiency theory are the most widely used basic theories. According to the pare to-efficiency theory, the incubator can cultivate the N.E. with the most potential and in line with the regional economic development through the comprehensive evaluation of N.E. development. And according to the enterprise life cycle theory, the resource input in the initial stage of N.E. should be strengthened, so as to improve the efficiency of incubation resource allocation and reduce the cost of resource allocation. In addition, based on the $\mathrm{X}$-efficiency theory, the incubator should pay attention to the collaboration with new enterprises, and assist N.E. to improve their management and form an incubation culture, so as to reflect the X-efficiency of the entire incubation network.

H5: A hierarchical regulation of the incubation process for a N.E. has a positive impact on incubation efficiency.

H6: Knowledge resource and service resource have positive effects on the improving incubating-efficiency.

2) The Characteristics of Incubation Analysis Base on Entrepreneurial Factors

As an important branch of entrepreneurial research, the study of the incubator is based on the analysis of the entrepreneurial elements. By analyzing the influencing factors of entrepreneurial activity, it is helpful to improve the incubating-efficiency. The main influences are as follows:

a) Environmental factors

The incubator operation is based on the entrepreneurial activity, and the en- 
trepreneurial environment construction ability is also one of the duties of the incubator, as well as one of the factors influencing the incubation efficiency.

b) The risk perception factor

While creating a stable environment, the incubator focuses on reducing participants' perception of environmental risks, which can guarantee N.E.'s confidence in success and external resource intervention and improve incubating-efficiency.

c) Policy factor

Entrepreneurial activity has regional characteristics and is influenced by regional social structure network and policies. Incubator should construct policy incubation resources with regional feature based on that characteristics of regional policies.

d) Institutional factor

The modern business system was originally designed for mature enterprises, not new ones. Incubator incubating-efficiency is the basis of creating a suitable for the development of N.E. internal institutional environment, decrease the barriers to entry of opening, policy and system to reduce volatility influence on the development of N.E., this also is the incubator as entrepreneurial public policy tools to the existence of the mission.

e) Entrepreneurial opportunities

Based on the research of CPSED, incubators should help N.E. to explore entrepreneurial opportunities and improve the incubation efficiency by increasing entrepreneurship training for N.E [6].

f) Incubation process management

Learn from PESD's measure criteria for N.E., the incubator should design the input of incubation resources for different phases of N.E. development.

H7: N.E. sales can reflect incubating-efficiency levels.

H8: The stable cultivation environment constructed by the incubator has a positive influence on the incubating-efficiency.

3) Incubating-efficiency Impact Factors

a) Entrepreneurial finance factor

After the external financial resources are transformed into internal resources by the incubator, they are called as incubating financial resources. Through this symbiotic partnership, the overall incubation efficiency will be improving. It can be seen from that point of view of an incubator that the incubation financial service is carry out based on the proxy mode to solve the problem of incubation finance and obtain the necessary profit. From the perspective of VC: participating in this partnership can reduce the investment cost of the project, improve the perception of investment trust, and make investment more efficient. From the perspective of N.E.: Funding within the incubator is cheaper and more stable.

b) Incubation network factor

Incubation network is an important way to obtain resources and reduce costs. The incubators of market operation are generally more efficient, and it is easier 
to embed N.E. into the existing value relationship network. The professional management and service team is the guarantee to improve the incubation efficiency of N.E. In practice, public incubators are at a disadvantage in terms of incubating-efficiency and lack the willingness to actively connect resources and integrate into the incubation network.

c) Incubating-resource construction methods

The operational cost of the incubator focuses on the cost of acquiring the incubation resources and information. There is a wide space for research on how to improve incubating-efficiency through virtualization and network operation.

d) Incubator performance criteria

The incubator has corporate attributes and the performance concept applies equally to incubators. For the incubator, efficiency improvement is the premise and foundation of performance management. The performance and evaluation system can promote the improvement of incubating-efficiency, and the single profit index is not helpful to the improvement of incubating-efficiency. Incubator performance needs to consider the interaction between N.E. and the internal and external factors of the incubator. This also reflects the importance of process and dynamic management for the improvement of incubating-efficiency. The research on the incubating-efficiency can better grasp the key indicators of the incubator performance and help to improve the performance management effect of the incubator. From the traits of incubating-efficiency, it can be measured in terms of output and cost. In practice, the incubator has more control over input than output.

e) E.O. (Entrepreneurial orientation)

Helping N.E. adopt the E.O. strategy will help improve the innovative performance of the enterprise. The incubator should make full use of the E.O. of the public sector and other organizations on N.E., help N.E. share the entrepreneurial risks in a highly dynamic environment, and enhance the willingness of N.E. to innovate. In addition, resources of the incubator should be strengthened in infrastructure, business support, innovation cooperation platform and foreign exchange platform construction, and the incubation environment should be improved.

\subsection{Overview of Incubators \& Incubation in Zhejiang, PRC}

Founded in 1990, Hangzhou high-tech new development center is the first incubator in Zhejiang province. China's first incubating-complex area is established in Ningbo in 2016, and so far, the incubator industry in Zhejiang province is in the leading position in China. The market competition is full, the entrepreneurial atmosphere is good, the support funds are huge, the talent density is high, and the degree of internationalization is high. These are the advantages of Zhejiang Province in the field of entrepreneurship, and also provide the foundation for the development of the incubator industry.

In the view of the incubator's type, the incubator in Zhejiang province has 
formed the pattern of co-development of university science and technology park, overseas study start-up park, college student start-up park, professional technology incubator and other types. In view of regional distribution, Hangzhou and Ningbo are more centralize and forms that trend of the development of incubator clusters in the ring-Hangzhou bay area with abundant talent resources. From the perspective of business model, entrepreneurship coffee, professional industry-incubating incubator, incubation complex and Small town with industry characteristics are the most mainstream operation mode of the incubator in Zhejiang province. Especially it should be noted that incubator, which is in Zhejiang Province, provide entrepreneurial training and consulting services for N.E., what is the annual average of only 7.2, which is lower service frequency. In view of government management, that the thinking of business management is maintain and the business environment is not improved, exit mechanism is not established, the re-construction is serious, and the low incubating-efficiency is tolerated.

\section{Methodology}

This article on the research design adopted the combination of qualitative and quantitative methods. The implementation route of the research method is shown in Figure 3.

\subsection{Quantitative}

Based on literature and hypothesis, the framework of factors affecting incubating-efficiency and the measurement variables of DEA model were established. As shown in Figure 4.

In this paper, I.V. has 3 dimensions for a total of 5; D.V. has a total of 2, as shown in Table 1.

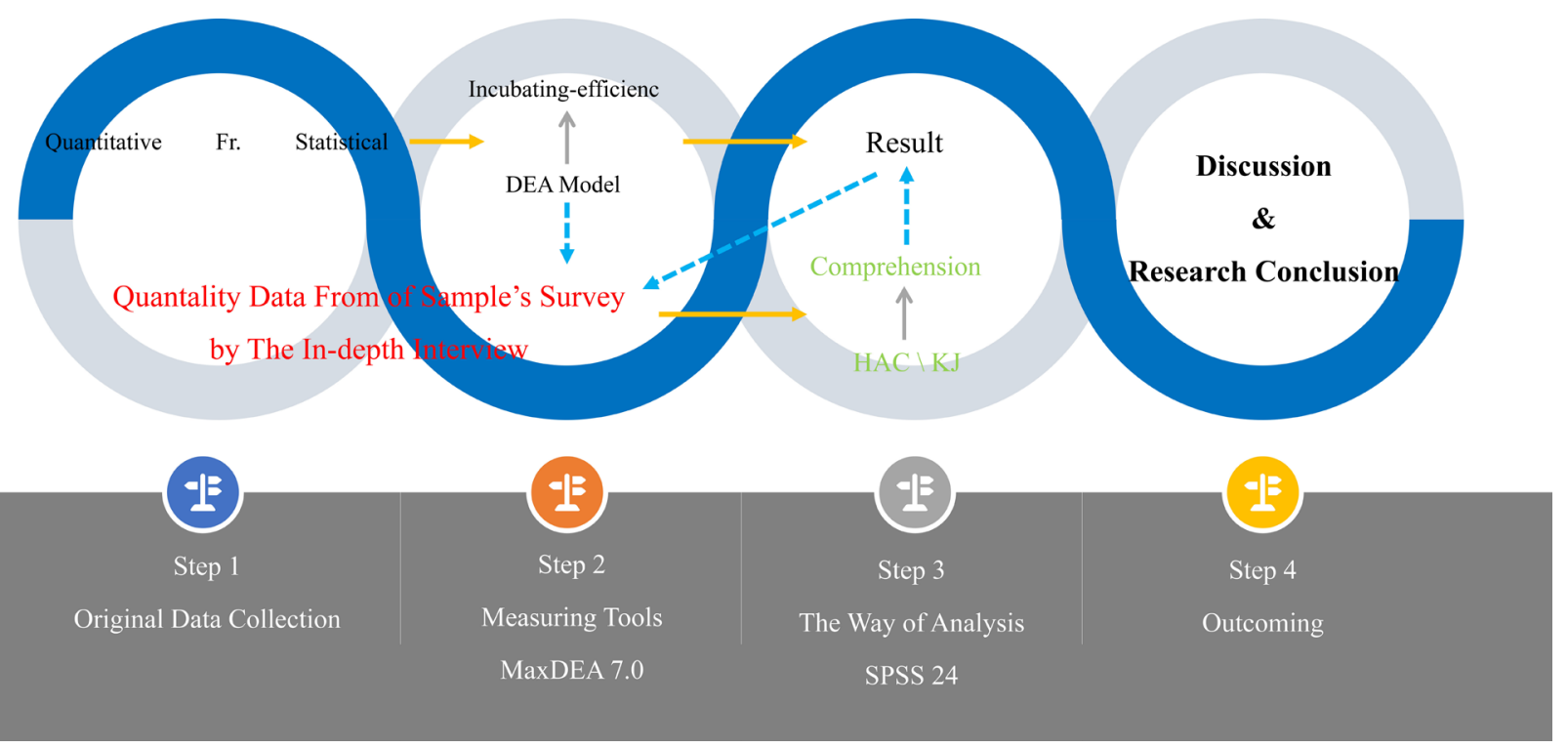

Figure 3. Implementation route of Methodology. 


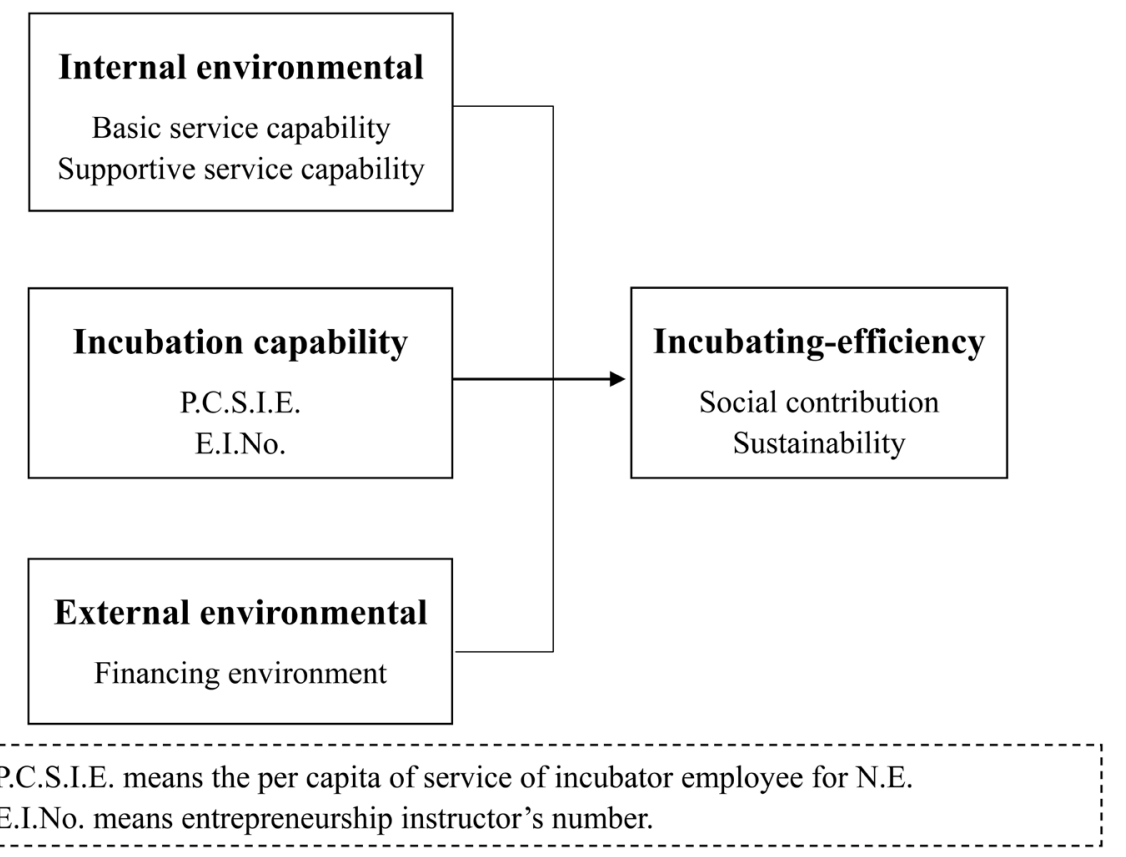

Figure 4. Impact Factors Framework of incubating-efficiency.

Table 1. Incubating-efficiency I.V. and D.V.

\begin{tabular}{ll}
\hline & X1: Basic service \\
& X2: Supportive service \\
I.V. & X3:P. C.S.I.E. \\
& X4: Entrepreneurship instructor \\
& X5: Financing aid \\
& Y1: Social contribution \\
D.V. & Y2: Sustainability \\
\hline
\end{tabular}

1) Samples and Sampling

By June 2017, Hangzhou, Ningbo and Jiaxing were among the top three in terms of the number of incubators at the provincial and national levels, it is 76.76\%.The above data comes from Association of Zhejiang Province science and technology business incubators.

The sample was sampled by snowball sampling. Selection criteria: 1) comprehensive; 2) the longest establishment time; 3) the largest scale. According to the distribution of the overall sample of incubators in Zhejiang Province (incorporated by statistical monitoring), 15 incubators in areas with relatively concentrated development of incubators such as Hangzhou and Ningbo will be selected as samples for DEA calculation. It is selected as the sample unit listed in Appendix I.

2) DEA model

Combined with the characteristics of the research problem, sample acquisition and data structure, this paper adopts DEA method to measure the incubating-efficiency. From the characteristics of entrepreneurship activities and the incubation process of N.E., it is easier for the incubator to grasp the resource at 
the input end. In addition, the incubator is in a state of variable return on scale and the cultivation of N.E. is a dynamic management process in actual operation. The incubating-efficiency can be affected by such factors as the scale of incubator, coordination capacity and external environment. Therefore, the non-oriented DEA Model (input-prioritized) is selected to analyze the incubating-efficiency. At the same time, according to the development status and operation characteristics of the incubator industry in Zhejiang province, this paper adopted the radial distance calculation of some indexes and the mixed algorithm of non-radial calculation for the model parameter setting. The model planning type is as shown in Formula (1). The TE and PTE of the sample incubator were measured, and the incubating-efficiency grade and influencing factors were analyzed on this basis. Provide information support for future in-depth interviews.

$$
\begin{array}{ll}
\min \beta=\frac{1-\frac{m_{1}}{m}(1-\theta)-\frac{1}{m} \sum_{i=1}^{m_{2}} S_{i}^{N-} / x_{i k}^{N}}{1+\frac{q_{1}}{q}(\varphi-1)+\frac{1}{q} \sum_{r+1}^{q_{2}} S_{r}^{N+} / y_{i k}^{N}} \\
\text { s.t. } \quad X^{R} \lambda+S^{R-}-\theta x_{K}^{R}=0 \\
& X^{N} \lambda+S^{N-}=x_{K}^{N} \\
& Y^{R} \lambda-S^{N+}-\varphi y_{K}^{R}=0 \\
& Y^{N} \lambda-S^{N+}=y_{K}^{N} \\
& \lambda, s^{-}, s^{+} \geq 0
\end{array}
$$

3) Data Collection and Analysis

The important data needed for the efficiency measurement of incubators in Zhejiang province are the Statistical Yearbook, government policies and interpretation documents of the ministry of science and technology, Zhejiang provincial government and the national Torch center. The 2017 China Torch Yearbook is the main data source of the model. Through data processing by MaxDEA software, effective DMU can be obtained.

Specifically, multiple input and output indicators need to be determined when using DEA model to calculate. The use of statistical data includes the input index and output index of the incubator. In terms of the indicator collection method refer to the research of Xin Wang et al., as well as the related documents of the official incubator management in Zhejiang province [7]. In this paper, the input indexes of incubation resources are divided into material resources and service resources. Material resources include the incubation funds input and the area of incubation site; Service resources include the range of incubation services, number of entrepreneurial advisors, and gain to external investment and financing aid. Incubator, as a commercial infrastructure and public policy tool, should take into account social benefits in addition to economic benefit in that setting of output variables. Therefore, the selection of output indicators includes employment number and total income of the incubator.

In the quantitative research part (Figure 5), adopted the data from government statistical yearbook. The data is characterized by stable structure, high re- 
liability and scientific and unified method. In addition, the non-oriented DEA Model (input-prioritized) was adopted in the research and analysis, which is a linear programming method without dimensionality and preprocessing and is widely used in related efficiency studies. Therefore, the quantitative research in this paper does not need to test the reliability and validity.

The DEA Model measures the sample situation as shown in Table 2.

\subsection{Qualitative}

The survey object was the incubator, entrepreneurship research institution and government regulatory agency included in the statistical monitoring of Zhejiang province.

1) In-depth interview object

The total number of in-depth interviews in this paper is 21 , and the selection standard are shown in Table 3 and Table 4.

2) In-depth interview Implement

The process and structural design of the interview referred to Kvale's research [8]. It is to learn about substantive issues related to resource allocation and research incubators, incubator business processes, new business and so on. The in-depth interview outline is shown in Appendix II.

\section{Results and Discussion}

\subsection{The Results of Quantitative and Qualitative}

1) DEA Model results

The DEA model's measuring index of incubating-efficiency as shown in the Table 5.

The sample indicators are normalized, and the specific data after conversion is shown in Table 6.

The details of general statistics of DMUs by DEA is shown as Table 7. The algorithm of model was taken by Hybrid Distance (Radial and SBM Fields, Non-Oriented, Input-priorized) ${ }^{3}$.

The deviation values of STDEV.S of DMUs were calculated as TE $=0.271$, $\mathrm{PTE}=0.851$ and $\mathrm{SE}=2.338$ (rounding approximation with 3 decimal places reserved was processed). By comparing the STDEV. P values, it can be seen that the overall incubating-efficiency level in Zhejiang Province is similar to the sample incubator's efficiency level distribution, and the sample representative is better. As shown in Table 8.

The specific numerical distribution of Hybrid Model for DMUs estimation is shown in Table 9. Combined with the results in Table 8, it can be concluded that the lowest value of TE of the measured DMU is about 0.093 , the highest value is 1 , and the mean value is 0.842 . The differences in the deviations of TE, PTE and SE confirmed the intergenerational differences in the development lev-

${ }^{3}$ Hybrid equals radial model, if all measure index set-up was radial. Hybrid equals SBM model, if all measure index set-up was non-radial. 
el of the incubating-efficiency between the incubators in the region. In addition, from the proportion of DMU, the effective ratio of incubating-efficiency of Zhejiang incubator is about $66.667 \%$. Among them, the effective proportion of PTE is $80 \%$, and that of SE is $66.667 \%$. In the case of RTS, the "SE" has to be improved more than the PTE, and the scale of the incubation industry is out of balance, and about a third of the incubators are in the IRS.

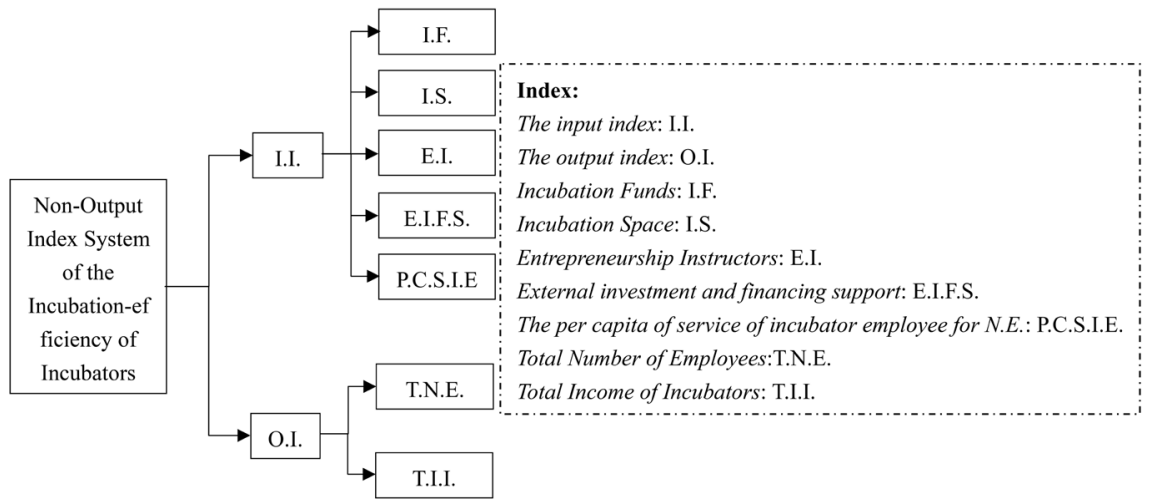

Figure 5. The Non-output index system of incubating-efficiency of incubators.

Table 2. The Summary of Measure DMUs.

\begin{tabular}{|c|c|c|c|c|}
\hline ITEM OF INCUBATOR & LOCATION & LEVEL/TYPE & ESTABLISH & DMU CODE \\
\hline $\begin{array}{l}\text { Ningbo Yinzhou Yinchuang En- } \\
\text { trepreneurship Park } \\
\text { Management Services Ltd. }\end{array}$ & NINGBO & STATE & 2012 & BI1 \\
\hline $\begin{array}{l}\text { Zhejiang University Science Park } \\
\text { Ningbo Development Ltd. }\end{array}$ & NINGBO & STATE & 2001 & BI2 \\
\hline $\begin{array}{c}\text { Ningbo Yinchuang } \\
\text { Technology Incubator } \\
\text { Management Services Ltd. }\end{array}$ & NINGBO & STATE & 2008 & $\mathrm{BI} 3$ \\
\hline NNUSP VENTURE PARK & NINGBO & STATE & 2009 & BI4 \\
\hline $\begin{array}{l}\text { Hangzhou Lefu Zhihui } \\
\text { Park Incubator Co., Ltd. }\end{array}$ & HANGZHOU & STATE & 2010 & BI5 \\
\hline $\begin{array}{c}\text { Hangzhou Dongbu Software Park } \\
\text { Ltd. }\end{array}$ & HANGZHOU & STATE & 2001 & BI6 \\
\hline $\begin{array}{l}\text { Zhejiang Yinjiang } \\
\text { Incubator Ltd. }\end{array}$ & HANGZHOU & STATE & 2007 & BI7 \\
\hline $\begin{array}{l}\text { Hangzhou Science } \\
\text { and Technology } \\
\text { Industrial Park } \\
\text { Technology Innovation } \\
\text { Service Center }\end{array}$ & HANGZHOU & STATE & 1990 & BI8 \\
\hline $\begin{array}{l}\text { Hangzhou Yuhang Hi-tech In- } \\
\text { dustrial Park Incubator Ltd. }\end{array}$ & HANGZHOU & STATE & 2007 & BI9 \\
\hline Bee-Hivein The Dream Town & HANGZHOU & STATE & 2015 & $\mathrm{BI} 10$ \\
\hline The 7th Space & HANGZHOU & STATE & 2016 & BI11 \\
\hline
\end{tabular}




\section{Continued}

\begin{tabular}{|c|c|c|c|c|}
\hline $\begin{array}{l}\text { Jiaxing Technology } \\
\text { Innovation Service Center }\end{array}$ & JIAXING & STATE & 1999 & BI12 \\
\hline $\begin{array}{l}\text { Zhejiang Xiuzhou Huigu } \\
\text { Technology Innovation Center }\end{array}$ & JIAXING & STATE & 2009 & BI13 \\
\hline $\begin{array}{c}\text { Jinhua Science Park } \\
\text { Innovation Service Center Ltd. }\end{array}$ & JINHUA & STATE & 2001 & BI14 \\
\hline $\begin{array}{l}\text { Wenzhou Hi-tech Industrial Park } \\
\text { Innovation Center }\end{array}$ & WENZHOU & STATE & 2001 & BI15 \\
\hline
\end{tabular}

Table 3. The namesof in-depth interview.

\begin{tabular}{|c|c|c|}
\hline INTERVIEWEES & UNITS & POSITION/ROLE \\
\hline Q. X. Kong & Ningbo Yinzhou Yinchuang Entrepreneurship & Manager \\
\hline Z. Zhang & Park Management Services Ltd. (NYYCEP) & Entrepreneur \\
\hline C. L. Zhao & \multirow{2}{*}{ Yonggang Modern Park (YGMP) } & Manager \\
\hline Z. H. Ying & & Entrepreneur \\
\hline B. Liu & Yinzhou Business Incubating & Manager \\
\hline L. Liu & Development Area (YBIDA) & Entrepreneur \\
\hline Y. Shi & \multirow{2}{*}{ iINCUBATOR Co., Ltd. } & Manager \\
\hline Z. F. Xu & & Entrepreneur \\
\hline Y. P. Zhang & Hangzhou Lefu Zhihui Park & Manager \\
\hline Eunice & Incubator Co., Ltd. (LFZHP) & Entrepreneur \\
\hline X. X. Tang & Hangzhou Hi-tech Industrial Park & Manager \\
\hline X. B. Xia & Entrepreneurship Services Center (HZHIP) & Entrepreneur \\
\hline H. F. Luo & \multirow{2}{*}{ Nanhu S \& T Incubation Services Center (NHST) } & Manager \\
\hline G. Chen & & Entrepreneur \\
\hline B. Zhu & \multirow{2}{*}{ Jiaxing S \& T Incubation Center (JXSTI) } & Manager \\
\hline X. Xiao & & Entrepreneur \\
\hline F. Xu & \multirow{2}{*}{$\begin{array}{l}\text { Jinhua Science Park Innovation Service Center Ltd. } \\
\text { (JHSPI) }\end{array}$} & Manager \\
\hline Y. W. Zhou & & Entrepreneur \\
\hline X. T. Xia & $\begin{array}{c}\text { Zhejiang Science and Technology } \\
\text { Business Incubator Association (ZSTIA) }\end{array}$ & Administrator \\
\hline Eric Lam & The Hong Kong Polytechnic University, China (HKPU) & Researcher \\
\hline J. Qin & Nankai University, China (NKU) & Researcher \\
\hline X. L. Tang & Ningbo Dahongying University, China (DHYU) & Researcher \\
\hline
\end{tabular}

Table 4. Theselection Criterion of interviewee.

\begin{tabular}{ccc}
\hline Dimensione & Type & Remark \\
\hline P.R & I & Specialist, Prof, Researcher; \\
& II & The senior management of incubator; \\
PID & III & Govemment Regulator, Investor; \\
& IV & NE, Staff, Business partner; \\
\hline
\end{tabular}




\section{Continued}

Description:

Professional researcher: PR

Practitioner in the Incubator Domain: PID

Type I: A specialist of Incubator, who focus on the research development of incubator in china for long time.

Type II: The man is an operator or management of incubator.

Type III: Person, who is an owner or investor or officer of govemment, is the main supervisor. Type IV: The incubator service object, including the Ne and extemal personnel with business relations.

Table 5. The measure index of incubating-efficiency.

\begin{tabular}{|c|c|c|}
\hline Input-Output Factors & Variable & Determination Index \\
\hline D1: & X1: Basic Service & i1: Incubation Space \\
\hline Interior Environment & X2: Support Service & i2: Incubation Funds \\
\hline \multirow{2}{*}{$\begin{array}{l}\text { D2: } \\
\text { The Capability of Incubation }\end{array}$} & X3: Service Range & $\begin{array}{l}\text { i3: The Per Capita of Service of } \\
\text { Incubator Employee for N.E. }\end{array}$ \\
\hline & $\mathrm{X} 4$ : Instructor & i4: Entrepreneurship Instructors \\
\hline $\begin{array}{l}\text { D3: } \\
\text { External Environment }\end{array}$ & X5: Financing Aid & $\begin{array}{l}\text { i5: External Investment and } \\
\text { Financing Support }\end{array}$ \\
\hline D4: & Y1: Social Contribution Degree & o1: Total No. of Employees \\
\hline Produce & Y2: Sustainable Development & o2: Total Income of Incubator \\
\hline
\end{tabular}

Table 6. The Input-output Indicators of Measure DMUs.

\begin{tabular}{cccccccc}
\hline DMUs & i1 & i2 & i3 & i4 & i5 & o1 & o2 \\
\hline BI1 & 32,066 & $15,525,000$ & 2 & 72 & $202,168,000$ & 1383 & $2,541,000$ \\
BI2 & 25,041 & $2,262,757$ & 2 & 22 & 113,878 & 1071 & $11,522,385$ \\
BI3 & 102,094 & $9,475,297$ & 4 & 14 & $4,500,050$ & 1150 & $11,498,157$ \\
BI4 & 20,000 & $25,000,000$ & 5 & 25 & $2,500,000$ & 450 & $14,705,882$ \\
BI5 & 31,781 & $2,828,447$ & 4 & 5 & $29,744,506$ & 1487 & $27,531,265$ \\
BI6 & 16,002 & 848,534 & 1 & 14 & $15,548,506$ & 685 & $112,706,389$ \\
BI7 & 39,553 & $2,545,602$ & 3 & 18 & $47,101,433$ & 783 & $4,742,365$ \\
BI8 & 91,195 & $2,201,380$ & 7 & 9 & $67,578,510$ & 1008 & $13,145,628$ \\
BI9 & 32,617 & 848,534 & 4 & 11 & 61,862 & 501 & $4,702,340$ \\
BI10 & 1200 & $5,000,000$ & 3 & 10 & $35,000,000$ & 150 & $1,657,300$ \\
BI11 & 1600 & $5,360,000$ & 5 & 6 & $43,100,000$ & 196 & $1,416,400$ \\
BI12 & 41,138 & 848,534 & 3 & 11 & $19,540,640$ & 1249 & $5,539,290$ \\
BI13 & 49,479 & 848,534 & 2 & 16 & $3,420,601$ & 1020 & $5,609,771$ \\
BI14 & 48,185 & $12,303,743$ & 2 & 25 & $136,175,228$ & 3142 & $7,802,360$ \\
BI15 & 147,540 & 848,534 & 2 & 27 & 156,129 & 1692 & $15,880,033$ \\
\hline
\end{tabular}


Table 7. The general statistics of DMUs by DEA.

\begin{tabular}{|c|c|c|}
\hline ITEM & SUM TOTAL & AVERAGE \\
\hline $\begin{array}{l}\text { Incubation Space } \\
\text { X1: I.S. }\end{array}$ & 679,491 & $45,299.4$ \\
\hline $\begin{array}{l}\text { Incubation Funds } \\
\text { X2: I.F. }\end{array}$ & $86,744,896$ & $5,782,993.067$ \\
\hline $\begin{array}{l}\text { The Per Capita of Service of } \\
\text { Incubator Employee for N.E. } \\
\text { X3: P.C.S.I.E. }\end{array}$ & 49 & 3.266666667 \\
\hline $\begin{array}{l}\text { Entrepreneurship Instructors } \\
\text { X4: E.I. }\end{array}$ & 285 & 19 \\
\hline $\begin{array}{l}\text { External Investment and } \\
\text { Financing Support } \\
\text { X5: E.I.F.S. }\end{array}$ & $606,709,343$ & $40,447,289.53$ \\
\hline $\begin{array}{l}\text { Total No. of Employees } \\
\text { Y1: T.N.E. }\end{array}$ & 15,967 & 1064.466667 \\
\hline $\begin{array}{l}\text { Total Income of Incubator } \\
\text { Y2: T.I.I. }\end{array}$ & $241,000,565$ & $16,066,704.33$ \\
\hline
\end{tabular}

Table 8. The summery eigenvalues of DMUs.

\begin{tabular}{|c|c|c|c|c|c|c|}
\hline $\begin{array}{l}\text { Classification } \\
\text { Effectiveness }\end{array}$ & $\begin{array}{l}\text { Min } \\
\text { Val. }\end{array}$ & $\begin{array}{l}\text { Max } \\
\text { Val. }\end{array}$ & Mean & STDEV.S & STDEV.P & $\begin{array}{c}\text { DMU Effective } \\
\text { Proportion of Sample }\end{array}$ \\
\hline$T E$ & 0.093 & 1 & 0.842 & 0.271 & 0.262 & $66.667 \%$ \\
\hline$P T E$ & 0.054 & 1 & 0.851 & 0.851 & 0.323 & $80 \%$ \\
\hline$S E$ & 0.549 & 10.013 & 1.587 & 2.338 & 2.259 & $66.667 \%$ \\
\hline \multicolumn{7}{|c|}{ Sample of RTS } \\
\hline \multicolumn{3}{|c|}{ Increasing (DMU No.) } & \multicolumn{3}{|c|}{ Constant (DMU No.) } & $\begin{array}{l}\text { IRS Proportion of Sam- } \\
\text { ple }\end{array}$ \\
\hline \multicolumn{3}{|c|}{5} & \multicolumn{3}{|c|}{10} & $33.333 \%$ \\
\hline
\end{tabular}

Remarks: Value Decimals 3 IRS: Increasing Returns to Scale; SE: Scale Effect Score Adoption of Hybrid Distance (Radial\& SBM) by DEA.

Table 9. The summery of hybrid model.

\begin{tabular}{ccccc}
\hline DMU & TE (CRS) & PTE (VRS) & SE & RTS \\
\hline BI1 & 0.54089 & 0.05402 & 10.01338 & Increasing \\
BI2 & 1 & 1 & 1 & Constant \\
BI3 & 1 & 1 & 1 & Constant \\
BI4 & 0.54915 & 1 & 0.54915 & Increasing \\
BI5 & 1 & 1 & 1 & Constant \\
BI6 & 1 & 1 & 1 & Constant \\
BI7 & 0.09286 & 0.06417 & 1.44698 & Increasing \\
BI8 & 0.63642 & 0.64616 & 0.98493 & Increasing \\
BI9 & 0.80392 & 1 & 0.80392 & Increasing \\
\hline
\end{tabular}




\begin{tabular}{ccccc} 
Continued & \multicolumn{3}{c}{} \\
\hline BI10 & 1 & 1 & 1 & Constant \\
BI11 & 1 & 1 & 1 & Constant \\
BI12 & 1 & 1 & 1 & Constant \\
BI13 & 1 & 1 & 1 & Constant \\
BI14 & 1 & 1 & 1 & Constant \\
BI15 & 1 & 1 & 1 & Constant \\
& Property & & Value & \\
& Distance & & Nybrid (Mixture of Radial and Non-radial) \\
& Orientation & & Scale Efficiency (CRS \& VRS)
\end{tabular}

From the results of the effectiveness of the incubating-efficiency, it is generally possible to judge whether the production capacity of the organization is fully released from the TE value grade, that is, whether there is a possibility of improvement in the DMU. At the same time, it can also judge the overall incubating-efficiency of the incubator, that is, the strong and weak incubation [7]. From the results of the RTS measurement of Hybrid Distance and the weight allocation of each stage, it can be seen that the overall incubation efficiency at VRS is higher than that at CRS. In other words, the incubating-efficiency is greatly affected by the change of scale efficiency, and the incubator can improve the TE through the improvement of SE. In addition, using the duality principle by DEA Multiplier Model measure, verify the efficiency of the sample measuring result is consistent, reflects the stability of incubating-efficiency measuring results. As the price information in the incubator inputs is palpable, as a result, this study further uses of the price information in the input index of incubator Allocative Efficiency (AE) was carried out to measure. $\mathrm{AE}$ is derived from the ratio of cost-efficiency and technical efficiency, which is that $\mathrm{AE}=\mathrm{CE} / \mathrm{TE}$. AE indicates the capacity of an incubator to use resources, which reflects the efficiency of transforming incubation resources into outputs. In the specific measuring of AE, considering that capital allocation is the core of resource allocation, this paper is based on i2 and i5 input indexes in DMU. Through calculation, the average value of AE of the incubator in Zhejiang province is 0.0958 , which means the incubator in Zhejiang has relatively low cost-efficiency and high-cost of management, reflecting the generally low-efficiency of the incubator management (Table 10).

2) The Operation of HAC

In order to further understand the difference in efficiency between incubators in Zhejiang province and better analyze the causes of the difference, this paper will use HAC to analyze the results of DEA.

$\mathrm{TE}$ reflects the overall TE of the incubator, while $\mathrm{AE}$ reflects the unit $\mathrm{AE}$ under the known conditions of the input price of incubation resources. The two re- 
flect the incubating-efficiency from different perspectives, but any indicator is not comprehensive enough to describe the incubation efficiency of the incubator. In order to make the incubation efficiency of all incubators more comprehensive and balanced when quantified, this paper takes TE, AE as the basis, and also refers to the efficiency values of PTE, SE and CE as the analysis basis of HAC. In addition, in the process of data processing, HAC has been verified that the results after standardization of original data are consistent with the direct application of original data analysis. In the case of HAC classification allocation, there are two results that can be divided into 3 groups and 2 groups. However, due to there's a small difference between the DMUs cluster in 3 groups, and no differences between the overall conclusion with 2 groups, in order to effectively find out the main factors affecting the incubating-efficiency. This paper adopts the conclusion that is divided into 2 groups. The measure is completed by SPSS 24 software, as shown in Table 11.

Table 10. The elaborating Results of A.E.

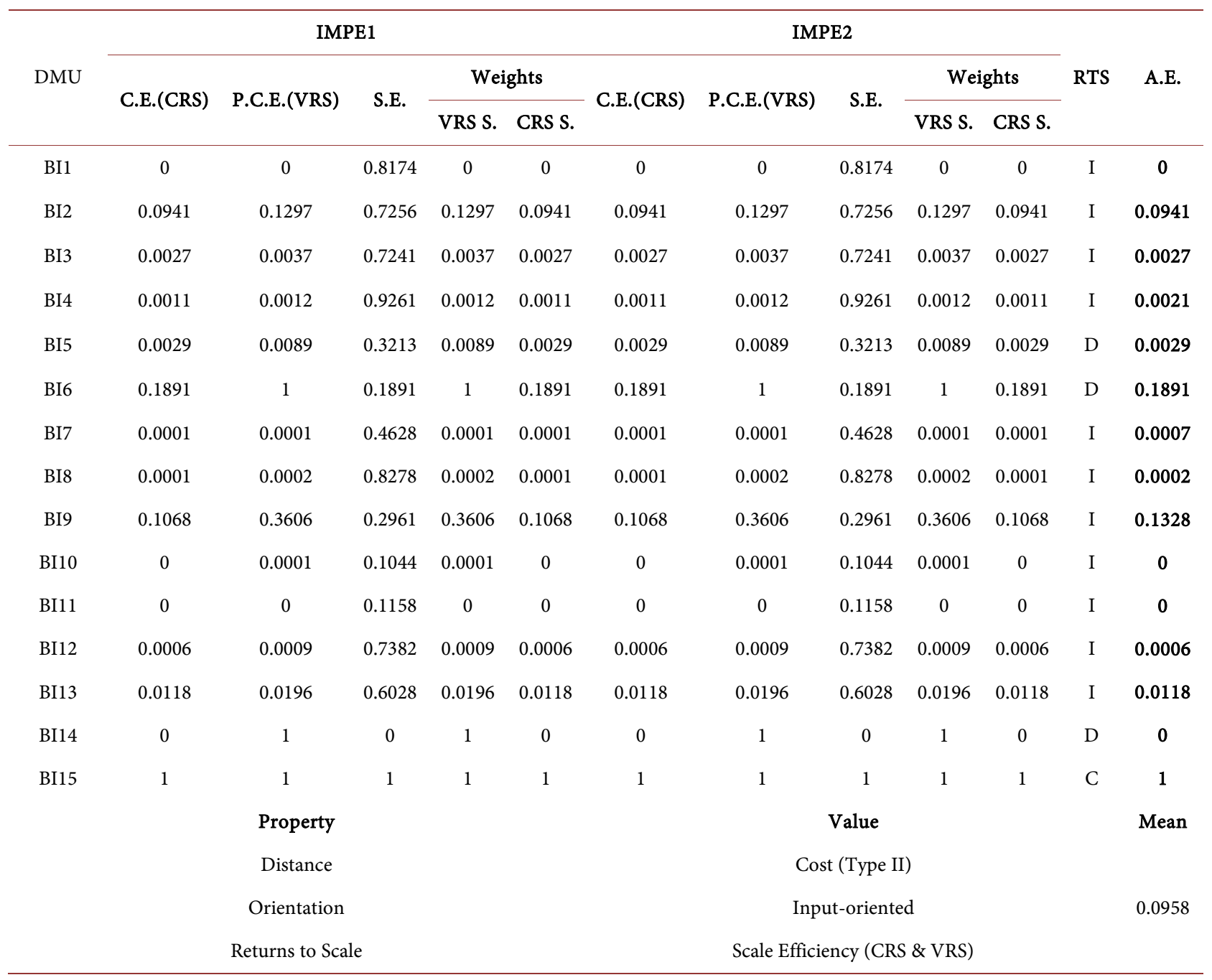

Remarks: C.E.: Cost Efficiency Score; P.C.E.: Pure Cost Efficiency Score; S.E.: Scale Effect Score; Value Decimals 4: I.: Increasing; D.: Decreasing; C.: Constant; A.E.: Allocative Efficiency. 
Table 11. Summarize note of cluster.

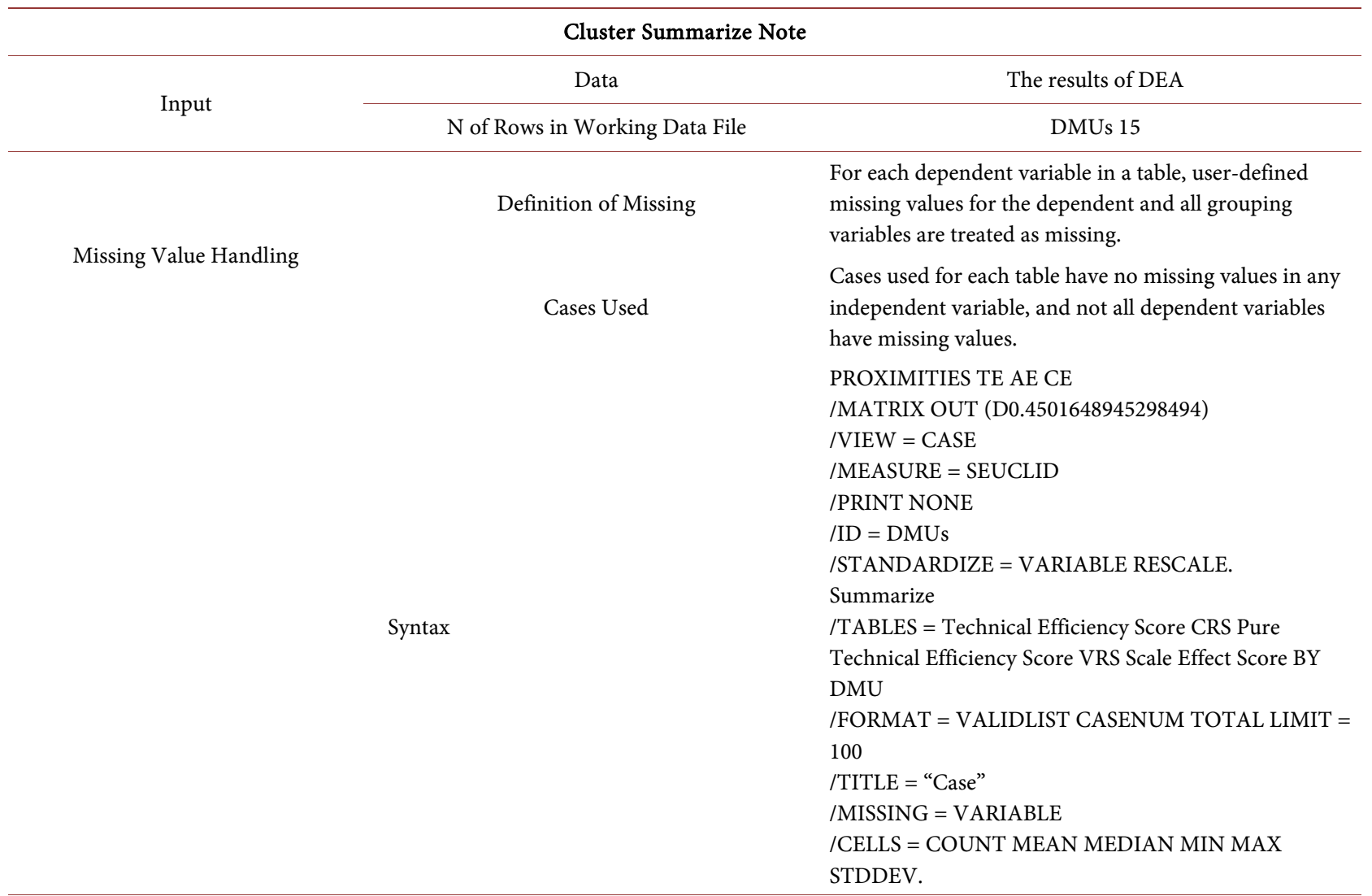

DMUs Processing Summary

\begin{tabular}{|c|c|c|c|c|c|c|}
\hline & \multicolumn{6}{|c|}{ DMUs } \\
\hline & \multicolumn{2}{|c|}{ Included } & \multicolumn{2}{|c|}{ Excluded } & \multicolumn{2}{|c|}{ Total } \\
\hline & $\mathrm{N}$ & Percent & $\mathrm{N}$ & Percent & $\mathrm{N}$ & Percent \\
\hline $\mathrm{TE}(\mathrm{CRS}) *$ Sample & 15 & $100.0 \%$ & 0 & $0.0 \%$ & 15 & $100.0 \%$ \\
\hline PTE $($ VRS $) *$ Sample & 15 & $100.0 \%$ & 0 & $0.0 \%$ & 15 & $100.0 \%$ \\
\hline \multirow[t]{2}{*}{$\mathrm{SE} *$ Sample } & 15 & $100.0 \%$ & 0 & $0.0 \%$ & 15 & $100.0 \%$ \\
\hline & \multicolumn{2}{|c|}{ Valid } & \multicolumn{2}{|c|}{ Missing } & \multicolumn{2}{|c|}{ Total } \\
\hline A.E./C.E. & $\mathrm{N}$ & Percent & $\mathrm{N}$ & Percent & $\mathrm{N}$ & Percent \\
\hline Squared Euclidean Distance used & 15 & $100 \%$ & 0 & $0 \%$ & 15 & $100 \%$ \\
\hline
\end{tabular}

3) The Results Analysis of DEA and HAC

First of all, the TE value is not yet effective, and there is some room for improvement. This also reflects that the overall incubating-efficiency of the incubator in Zhejiang is in an invalid state, and there is still room for improvement in the TE. From the perspective of TE, PTE and SE, the control ability of PTE and SE are different among incubators in the region, and the imbalance in the development of incubating-efficiency is generated, especially the imbalance in SE. Therefore, the incubator construction in Zhejiang province should focus on the full utilization of the resources already invested, control the expansion in 
scale and the re-constructing in hardware, and re-building the combination through the interaction of resources between the incubators, so as to improve the balanced development of the incubators in the region and the incubating-efficiency of individual incubators.

Secondly, according to the relationship between TE, PTE and SE, TE can be improved by improving the input of PTE or controlling the scale of SE to achieve the optimal incubating-efficiency of the incubator. The goal of strong and effective improvement of DMU efficiency is to achieve Pareto optimality. The improving was achieved by completing the proportion improvement first and then the Slack Movement, namely, Projection to Strong Efficient Frontier = Proportion Movement + Slack Movement. The improved path diagram is shown in Figure 6. Every incubator in Zhejiang currently has a two-way or single way improved operating space.

Thirdly, in the CRS state, BI1, BI4, BI7, BI8 and BI9 are in the RTS increasing phrase, while the rest DMU is in RTS (the scale return is stable). Starting from the scale effect of the current incubator, that is, the level of scale return and incubating-efficiency, the judgment can be made by the scale elasticity of DMU. In the VRS where PTE is separated, BI1, BI7 and BI8 are in DMU inefficiency, which indicates that PTE of BI1, BI7 and BI8 needs to be improved when the effect of SE is removed. From the proportion of samples, it can be inferred that about $20 \%$ of incubators in Zhejiang province have room for PTE improvement. The improvement of PTE is mainly due to the improvement of software, such as the entry of external factors which include entrepreneurial advisors, incubation funds, industry docking, and the synergy between resources through internal management, which leads to positive $\times$ efficiency.

Finally, HAC analysis is carried out on the basis of comprehensive DEA results, and it can be known that: All DMUs can be divided into 2 groups. Due to the significant difference between BI15 and cluster groups of other DMUs, BI15

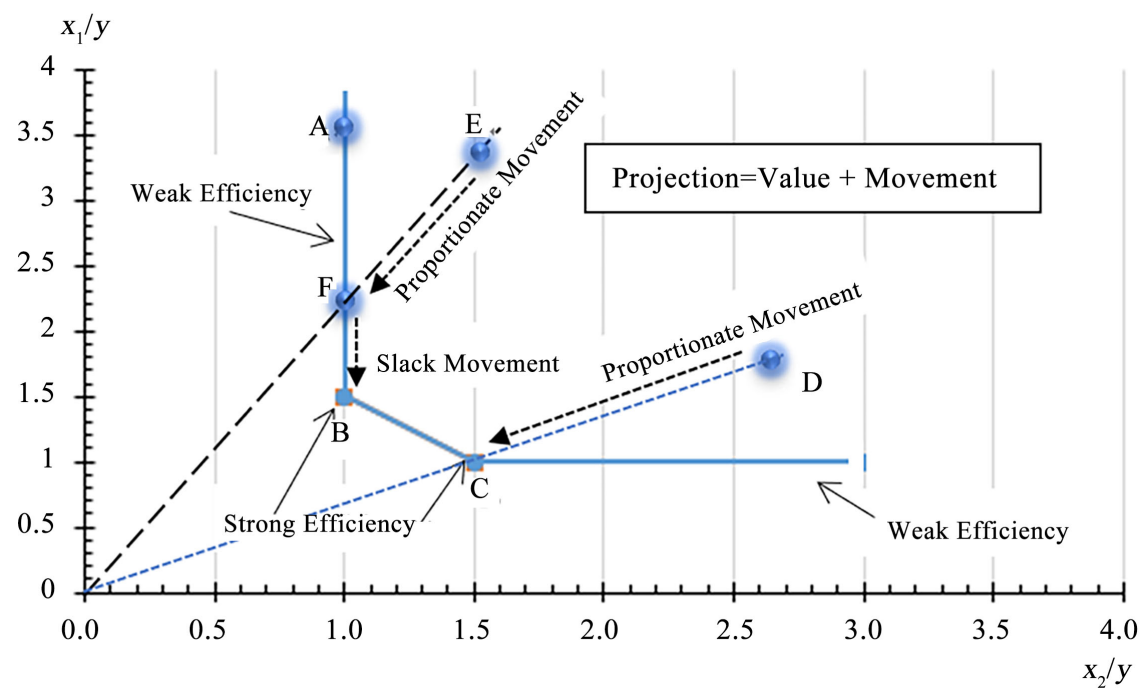

Figure 6. The demonstration of projection movement to strong efficient frontier. 
has a larger variability compared to other samples and is therefore individually listed as one group. For BI1 and BI7, there is a certain significance between the groups, but the performance is not outstanding, and the few differences of indicators can be ignored, so they can be separately merged into a small group in their major categories. Combined with the Hybrid Model, it can be found that the difference in incubating-efficiency between various incubators is mainly caused by $\mathrm{CE}$ and $\mathrm{AE}$. It is known that the relation between $\mathrm{AE}, \mathrm{CE}$ and $\mathrm{TE}$ is $\mathrm{AE}=\mathrm{CE} / \mathrm{TE}$. So, it can be clearly seen that the improvement of incubating-efficiency should be focused on the improvement of CE efficiency, that is, the main factor affecting the incubating-efficiency is CE.

4) In-depth interview

In addition to DEA model, this paper also conducted field survey on the operation and management of incubator. Through in-depth interviews with relevant personnel of the incubator, this paper further clarified the incubation status of the incubator in Zhejiang province, and verified the key indicators in the DEA model that had an impact on the incubating-efficiency in the actual operation of the incubator, and the hypothesis of the impact on the incubating-efficiency. It reviews that incubation condition of Zhejiang incubator and its incubating-efficiency improvement path from the perspective of qualitative research.

The In-depth interview program is shown as Appendix II. The key results were found from in-depth interviews, the meaning was considerable as the previous research.

During the interview, these members of researchers and experts focusing the field of incubators and entrepreneurship co-incited that the incubator needs to solve the problem of resource allocation and incubating-efficiency currently. The distribution of incubation resources in Zhejiang province is consistent with the development stage of the incubator. In addition, it is proposed that the incubator needs to evaluate the N.E. development phase and provide corresponding incubation resources targeted support, so as to improve the incubating-efficiency of the existing incubator.

In the process of summarizing the interview content, in order to express more clearly, the subjects of the incubation activity were combined. That is, the operation management personnel of the incubator and the N.E. operation management personnel are known as Incubating Activities Direct Participants. The interview results are summarized as shown in Table 12.

\subsection{Discussion of the Research Findings}

The findings were found from the DEA model and In-depth interview survey as Table 13 and the author's comments will be presents in the discussion.

According to previous sections of research and findings, can induce the relationship discussions as follow.

1) The discussion of findings as environment factor

This paper will discuss the incubation environment factors of incubator from the perspective of the regulators. 
First of all, for the government as the subject of regulation, at the macro market level, the government should create a business environment with transparent laws and regulations and let the incubators participate in fair competition.

Second, in terms of supportive policies for incubator development, government authorities need to act as a good coordinator, rather than conducting poverty-alleviation control on individual incubators. Further transform the function and mode of supervision and become the basic service provider and policy firewall for the incubation industry development.

Thirdly, policy orientation is an important factor to promote the rapid development of an industry. Inappropriate policy guidance will cause the incubator industry to fall into the bottleneck of development, resulting in re-construction and dilution of important resources.

In addition, as for the incubator operators, they would like to separate the basic services such as business registration, license representative and financial personnel agent from the operation and submit them to the specialized basic incubation platform for centralized processing. By focusing its resources on technology services, industry training, financial innovation and helping N.E. to connect with the external market, build a unique brand image and build an external resource network through strengthening cooperation, including links formed between incubators and incubators, governments, universities, enterprises, investment institutions, trade associations and other organizations. This external network is not only an important source of incubation resources, but also the basis of establishing a layered incubation system.

Finally, it is also necessary to protect against the emergence of systematic risks due to the supporting policy and incubator management. Both government regulators and incubator managers should strengthen the introduction of external investing institutions, properly restrict public investment (government support funds), improve the incubation efficiency through competition, and prevent systematic risks of "reverse elimination mechanism".

2) The discussion of findings as incubating ability

In Zhejiang province, the incubator construction, should pay attention to in the utilization of existing resources, pay attention to the import of professional resources on the basis of control scale, and strengthen the linkage between organizations, form an effective resource allocation network, improve the ability in incubation. Among them, the professional VC docking and high-level talent cooperated channel construction, is the key of the numerous incubation resources construction, which is also the important reason why many N.E. are willing to choose.

Table 12. Generalizing findings of In-depth Interview by KJ.

ROLE

\begin{tabular}{|c|c|c|c|}
\hline \multirow{2}{*}{ DIMENSION } & Administrator & Incubating Activities Direct Participant & Researcher \\
\hline & & In-depth Interview's Opinion Aggrega & \\
\hline
\end{tabular}




\section{Continued}

\begin{tabular}{|c|c|c|c|}
\hline Input & $\begin{array}{l}\text { Strengthening } \\
\text { resources } \\
\text { investment in } \\
\text { talent, } \\
\text { technology, } \\
\text { information and } \\
\text { government } \\
\text { services; }\end{array}$ & $\begin{array}{l}\text { To increase the capacity of financial services and technology services, to take control } \\
\text { of the premises and to the hardware facility; } \\
\text { Enhance the transparency of the evaluation of N.E., and implement the dynamic } \\
\text { evaluation of the whole process in the entry, incubation, graduation, exit, etc. } \\
\text { At the initial stage of entrepreneurship, N.E. hope that the E.I. can directly } \\
\text { participate in the operation, that is, become a partner and help the N.E. build a stable } \\
\text { management team. }\end{array}$ & $\begin{array}{l}\text { It is necessary for that } \\
\text { government to plan the } \\
\text { area and the industrial } \\
\text { distribution reasonably in } \\
\text { the construction of } \\
\text { incubator, so as to avoid } \\
\text { eduplication of } \\
\text { construction and vicious } \\
\text { competition due to policy; }\end{array}$ \\
\hline Process & $\begin{array}{l}\text { To Improve } \\
\text { incubating- } \\
\text { efficiency } \\
\text { through market } \\
\text { competition; }\end{array}$ & $\begin{array}{l}\text { Traditional property income and government subsidies are the main sources of } \\
\text { income; } \\
\text { Additional income such as the introduction of high-end talents, high-tech projects, } \\
\text { and filings has become a new profit point; } \\
\text { Configuring different resources according to the stage of N.E. development can } \\
\text { effectively improve the efficiency of incubating; } \\
\text { The incubator urgently needs to increase the number of professional operations } \\
\text { personnel and E.I., and improve the professional skills of existing staff; } \\
\text { Strengthen the capabilities of financial services and technology services, and control } \\
\text { the investment of hardware facilities such as venues; } \\
\text { Simplify unnecessary staff, improve the efficiency of the per capita in-service of } \\
\text { incubators, and increase the number and quality of E.I.; } \\
\text { Reducing low-quality entrepreneurial activities and formal liaison meetings, } \\
\text { introducing high-end professional venture capital institutions; } \\
\text { For N.E. in the development stage, it is hoped that the incubator can provide more } \\
\text { market opportunities and industrial channels, and E.I. can help N.E. to integrate into } \\
\text { the competitive market environment; } \\
\text { For newly graduated companies, they hope that the incubator can provide more } \\
\text { opportunities for contact with PE or VC. The E.I. can effectively design and manage } \\
\text { their finances and provide advice on IPO or capital market operations; }\end{array}$ & $\begin{array}{l}\text { Incubators conduct stable } \\
\text { and continuous evaluation } \\
\text { on the development of } \\
\text { N.E.; }\end{array}$ \\
\hline Output & $\begin{array}{l}\text { Change } \\
\text { assessment } \\
\text { criteria-Besides } \\
\text { social benefits, } \\
\text { economic } \\
\text { benefits should } \\
\text { also be } \\
\text { strengthened; }\end{array}$ & $\begin{array}{l}\text { The N.E. hopes that the incubator will continue to provide relationship information } \\
\text { after graduation, and build industrial support and cooperation channels among N.E.; }\end{array}$ & $\begin{array}{l}\text { Pay attention to nurturing } \\
\text { behaviors and sustained } \\
\text { entrepreneurial activity; }\end{array}$ \\
\hline $\begin{array}{l}\text { Environment } \\
\text { \& Innovation }\end{array}$ & $\begin{array}{l}\text { The diversity of } \\
\text { policy support; } \\
\text { Linkage between } \\
\text { regions and } \\
\text { social- } \\
\text { organizations to } \\
\text { form incubation } \\
\text { and information } \\
\text { network; }\end{array}$ & $\begin{array}{l}\text { Strengthen the incubator's specialization and industrial concentration; } \\
\text { All parties have strong intentions to strengthen cooperation between incubators; } \\
\text { It is hoped that the government will play a good role of coordinator, strengthen } \\
\text { industrial guidance and improve the market environment, and reduce administrative } \\
\text { interference in the operation of the incubator. In the park construction and function } \\
\text { planning, avoid the repeated construction or the bad competition between the } \\
\text { incubator due to the unreasonable policy design; } \\
\text { It is hoped that the government will change the funding method for incubators and } \\
\text { avoid the incubators from defrauding subsidies and diluting limited incubation } \\
\text { resources. } \\
\text { If the incubator can separate out the basic business services, focus on the allocation } \\
\text { of resources in the professional field, and raise the threshold for N.E. to enter the } \\
\text { incubator, it will effectively improve the incubation efficiency. } \\
\text { N.E. are not concerned about the nature of property rights or funding sources of } \\
\text { incubators, nor will they affect the choice of new companies. That is, irrespective of } \\
\text { the property of the incubator and the source of funds, the N.E. only pays attention to } \\
\text { whether it can more easily obtain the necessary resources and services from the } \\
\text { incubator; } \\
\text { Incubators should take the initiative to strengthen cooperation with regional } \\
\text { financial institutions and expand access to quality N.E.; }\end{array}$ & $\begin{array}{l}\text { Create a fair business } \\
\text { environment; } \\
\text { Directional support for } \\
\text { incubators; } \\
\text { Prevent systemic risks } \\
\text { arising from policies; } \\
\text { To build a new type of } \\
\text { incubating mechanism; }\end{array}$ \\
\hline
\end{tabular}




\section{Continued}

\section{Overlapping Consensus}

Admission Criteria, Dynamic Assessment: Concerned about the process of new enterprise growth, do a good job in assessing the entry and exit of new companies, and adjust the service approach.

Financial services: Actively help new enterprises obtain the necessary financial support, including PE or VC, industry-specific funds, government support funds; joint financial institutions, design targeted innovative financial products to ensure that new companies in the development process of funding needs.

Pay attention to HRM: The development of HR should be placed first in the incubator's operation and management, mainly including the establishment of the incubator's own professional team and the provision of HR support for the development of N.E.

Internal Incubating Environment Construction: The allocation and service content of incubation resources should be fair, transparent and standardized, create a reasonable and orderly competition within the incubator, and promote the flow of resources and cooperation among new enterprises within the incubator.

External incubating network construction: Strengthen the cooperation between incubators, incubators and other organizations, form a large incubation network, and break the barriers to circulation of new enterprises and incubation resources in different regions or between different incubators.

Table 13. The comprehensive results of findings.

\begin{tabular}{lllll}
\hline The Essential & $\begin{array}{l}\text { Measure } \\
\text { Dimensions }\end{array}$ & Hypotheses & DEA & H-Testing Key Findings
\end{tabular}

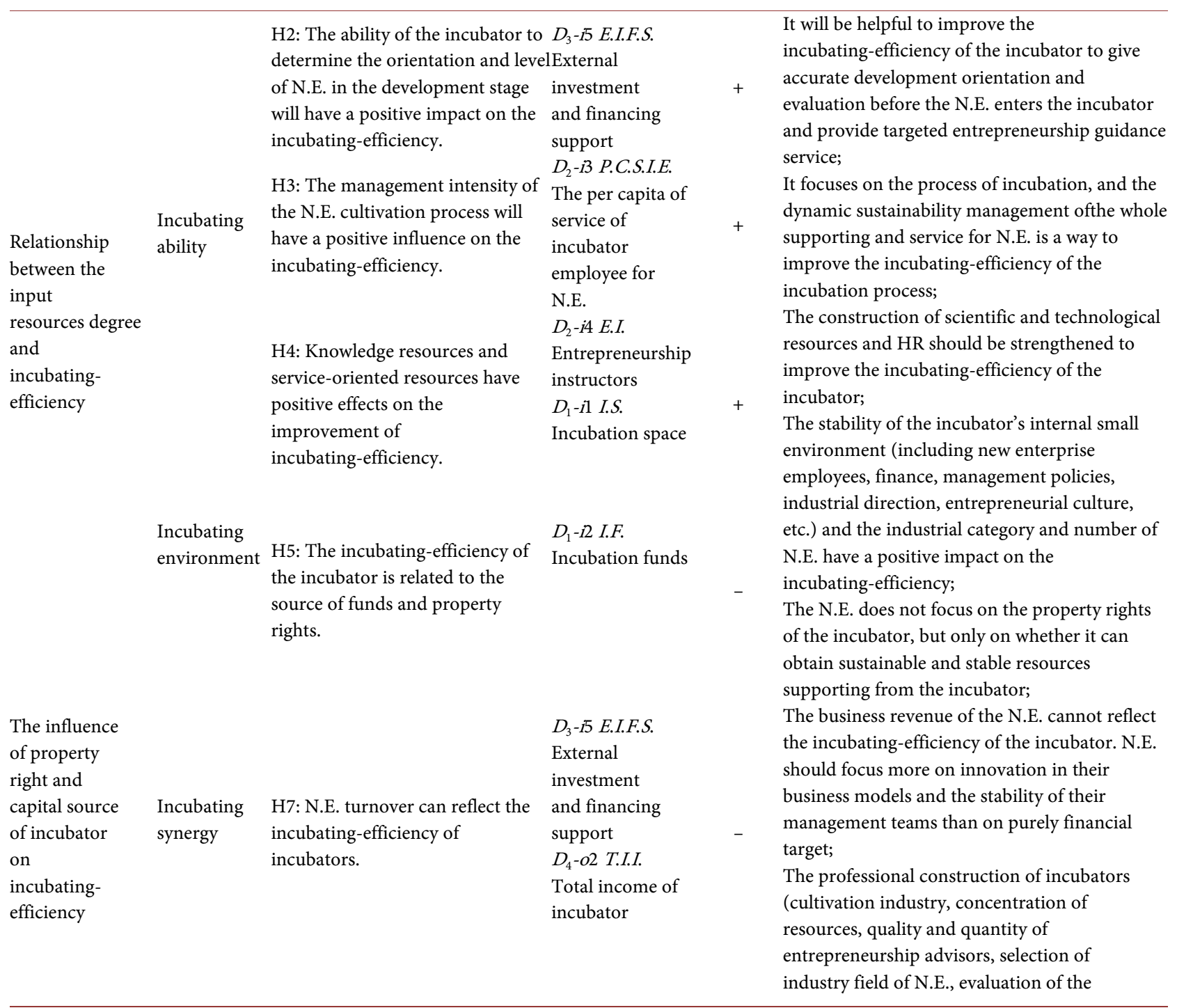




\section{Continued}

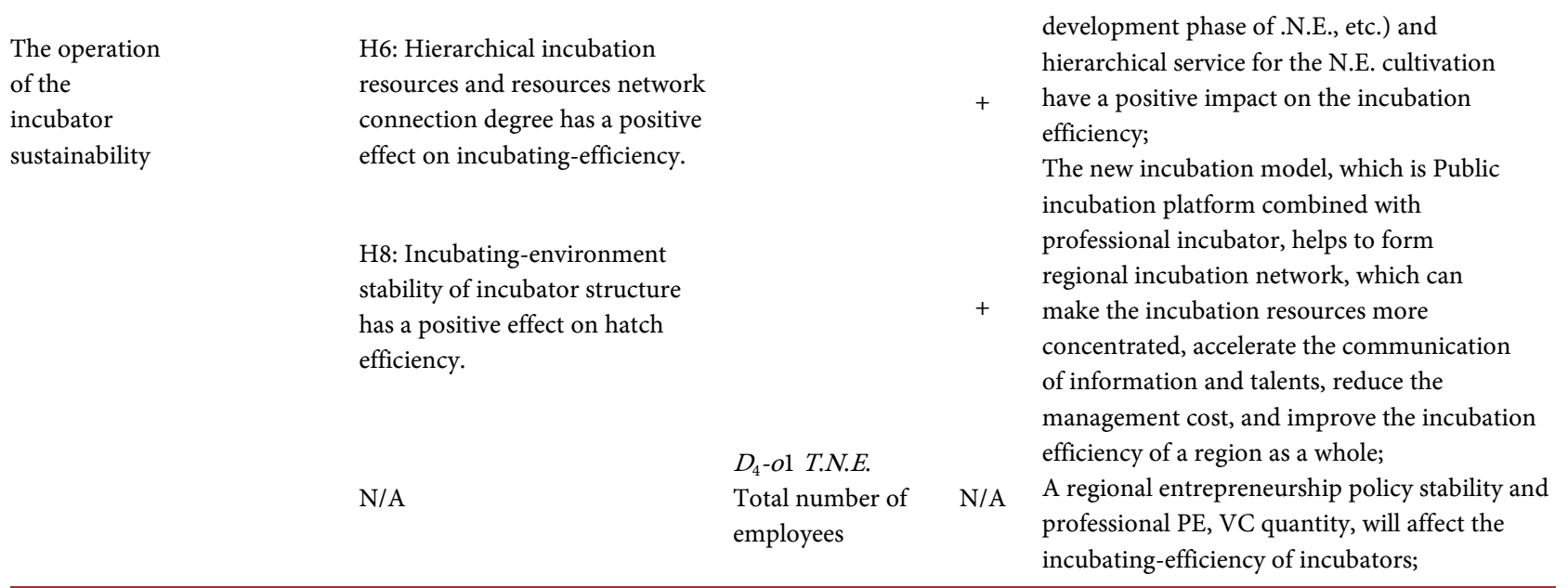

Notes: +, Positive/Influence; -, Negative/Deficiency; - +, Conditional Effects/Weak-positive.

It is that important mean of raising N.E. quality that the quality assessment of N.E. will directly influence the quality of incubating-efficiency. Effective startup education and stable small environment can avoid the competition from mature enterprises at the beginning, help N.E. to survive the most vulnerable infancy and promote the rapid growth of N.E. An incubator incubation quality depends largely on entrepreneurial advisor's advantages or disadvantages.

Finally, the incubation capability is also manifested in the ability that is the incubator to acquire an excellent N.E. Through the construction of its business brand and the development of market activities, try to expand the number of high-quality N.E., and pay attention to the distribution of industrial structure. This is also the basis of whether the incubator can carry out professional construction.

3) The discussion of findings as output factor

The incubating-efficiency grade will be reflected by the output of the incubator. As a profit organization participating in market competition and an incubator undertaking policy adjustment tools, its output should not only look at economic benefits, but also pay attention to social contributions.

Currently, the supervision and evaluation of incubators in Zhejiang Province overemphasizes the tax revenue and turnover generated by new enterprises. For the process to nurture and guide the industry does not emphasize, this is unreasonable. This paper believes that when judging the efficiency of an incubator, it should pay more attention to the contribution of its society, such as the employment impact of the region and the leading ability of industrial development. The incubator service object is the N.E.. The N.E. is different from the mature enterprise and is not competitive in terms of operational stability and profitability. More importantly, it can form a highland of talents, capital, technology, and information, so that relevant industry resources can gather and radiate around the incubator. This has extremely important social value for the sustainable de- 
velopment of a region.

From the results of model measure, the SE of incubators in Zhejiang Province is relatively low. In addition, the survey validated the research hypothesis and confirmed the path of incubator efficiency improvement based on literature theory and hypothesis and the feasibility of constructing a new efficient incubation model.

\section{Discussion}

\subsection{Overview of Incubators in Zhejiang, China}

First of all, from the point of industrial structure, incubator foster N.E. in Zhejiang province mainly in the electronic information technology, science and technology service industry, the traditional industry upgrade services, biological medicine, new materials, new energy technology, etc. The number of N.E. in the electronic information technology industry is the largest, including software development technology, microelectronics technology, computer and network technology, communication technology and other industries, accounting for about 60 percent of all incubated N.E..

Secondly, from the funding source for the incubator's operation, it mainly relies on government or non-profit organization's subsidies, and in terms of property rights, it belongs to government departments or social groups. Therefore, the actual profit pressure of the incubator is not stronger, which leads to the more traditional thinking of the operation and management of the incubator, and the efficient utilization of external resources has lost momentum. However, it is not entirely dependent on the market for the resources and the exploitation of the market.

In actual operation, the incubator industry in Zhejiang Province is not in a state of complete competition. To a certain extent, administrative barriers have caused the reverse elimination mechanism of the incubator industry. In recent years, with the acceleration of industrial iteration brought by technological changes, regional competition for talents and new technological resources has become increasingly fierce, thus changing the external environment of incubator operation. This is caused by the external environment on the efficiency of incubator industry improving pressure formation, namely the market environment forms the demand for efficiency, forcing the whole regional incubator incubating-efficiency of improvement extrinsic motivation.

Based on the development characteristics and regional industrial structure of the incubator in zhejiang province, the distribution proportion of the incubator in the region is shown in Figure 7.

\subsection{The New Incubating-Model}

The innovation of proposed hierarchical incubation and efficiency improvement model, combined hierarchical resources allocation mechanism with the feature so fvirtual and network, and the external environment of incubator operation is 
designed to be a perfect competitive market. It is in accordance with trend of future incubator development and has theoretical value of deep investigation. At the same time, when constructing the incubation industry, the government should pay attention to the new hierarchical incubation and efficiency improvement model, so that it becomes the reference blueprint and policy cornerstone of the incubator industrial strategic planning. The model is shown in Figure 8.

\section{Zhejiang Province}

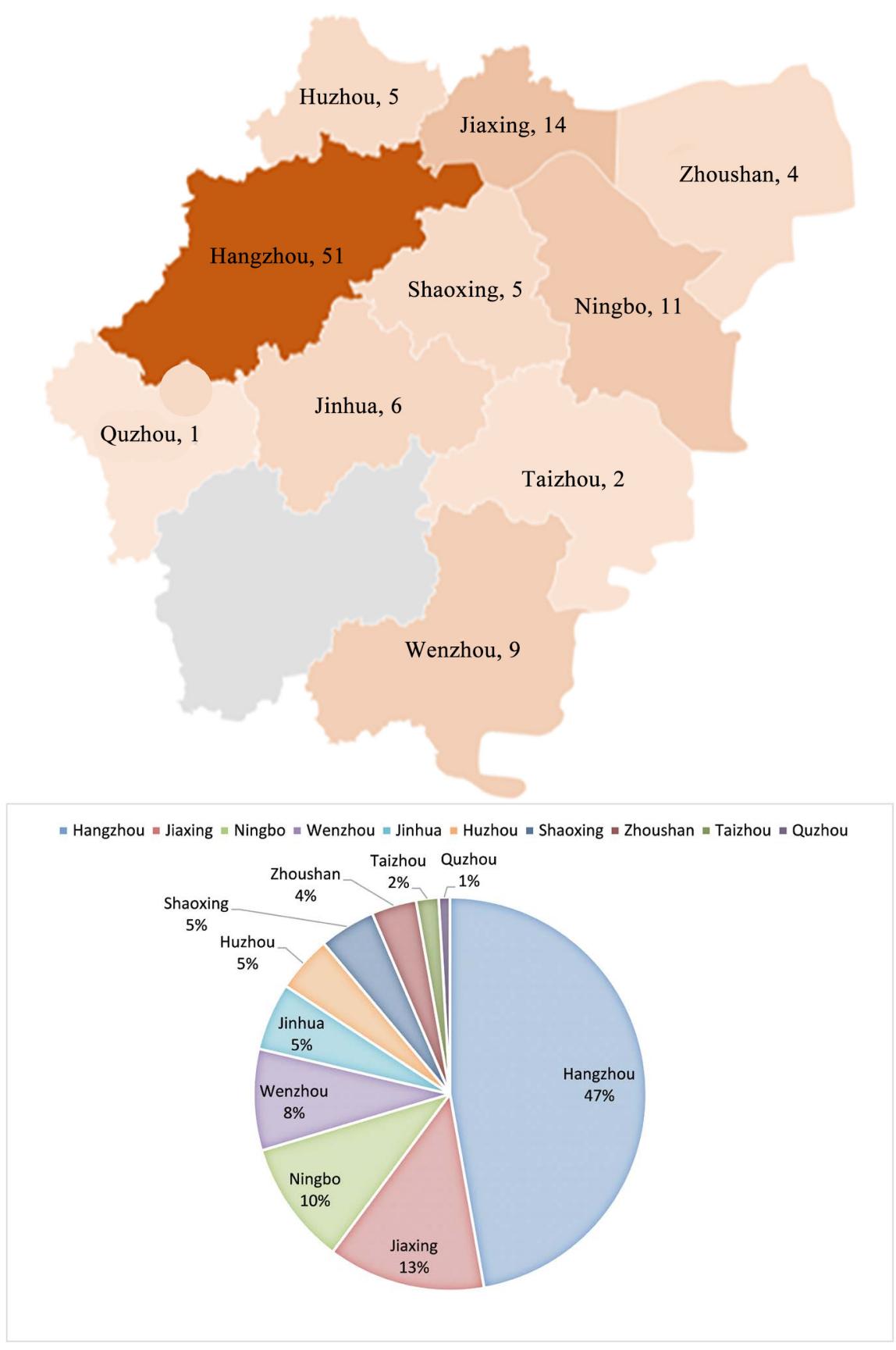

Figure 7. Incubators quantity distribution diagram in Zhejiang, China. 


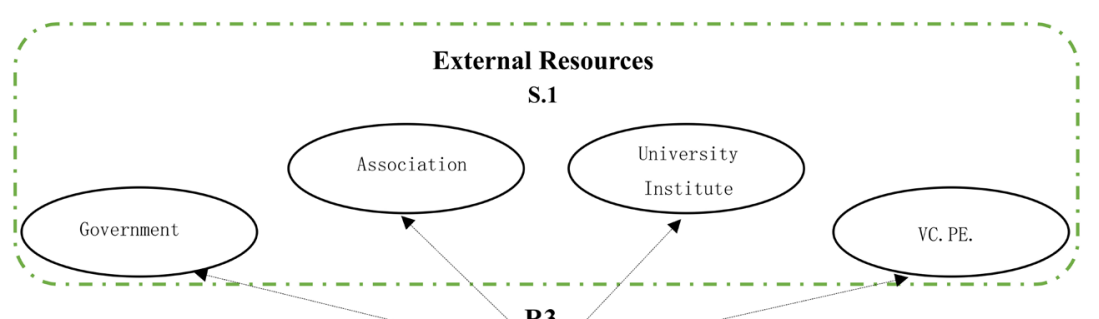

R3

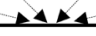

P-Public Platform of Entreprenuership Incubating

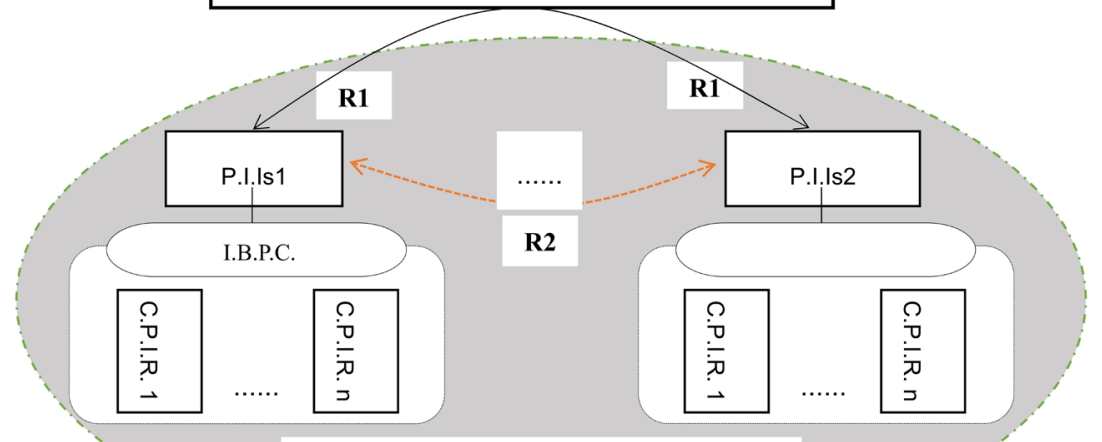

Professioanl or Industrial Incubators

S.2

Improving Efficiency Business Processing

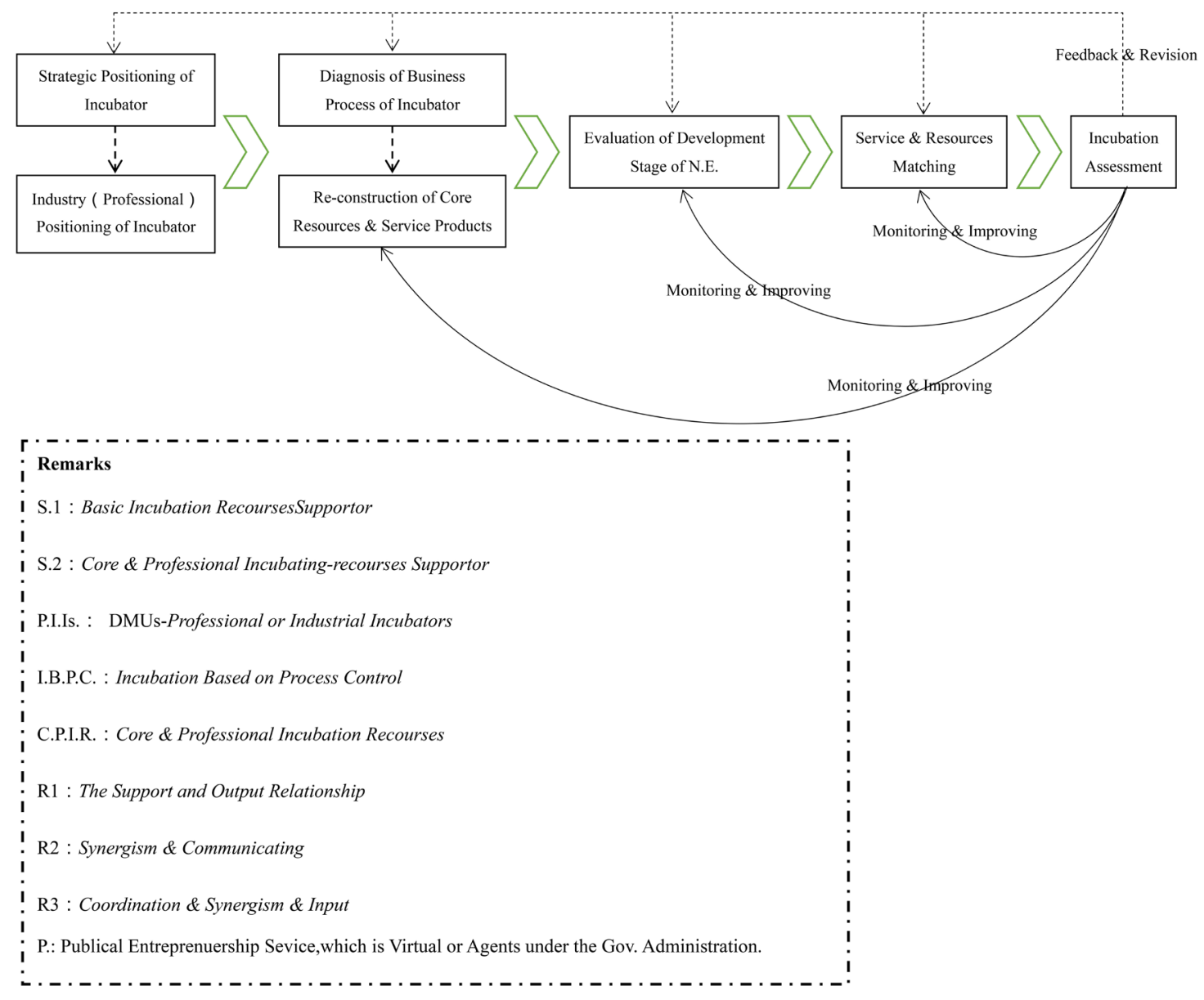

Figure 8. Thenewmodel of hierarchical incubating system and incubating-efficiency improving. 


\section{Conclusions}

This study explored the improving of incubating-efficiency from the perspective of the external environment, internal environment, and incubation factors. Through the computing of the incubating-efficiency of the sample, the key influencing factors of incubating-efficiency were analyzed. For the objectives of this study, the conclusions are as follows: Throughout the incubation process, including the N.E. before entering the incubator, during the cultivation process, after the graduation, give accurate development assessment, and provide targeted entrepreneurial counseling services, which will help the incubating-efficiency to improve. The internal tiny environment of incubator will impact on incubating-efficiency, including the richness of incubation resources, the sustainability of incubation services, the stability of the number of new businesses, and the professionalism of industrial positioning. When choosing an incubation platform, N.E. pay more attention to the industry positioning, business model, and service resource hierarchy of the incubator, and do not pay attention to the ownership of the incubator. Moreover, the number of PEs and VCs in the region will have an impact on the incubating-efficiency.

Eventually, an efficient incubation system based on the structured stratification of incubation resources was constructed to provide theoretical support for the improving of the incubating-efficiency of existing incubators.

\section{Recommendations}

The new model of hierarchical incubating system and incubating-efficiency improving in this paper (as shown in Figure 8) has a positive effect on reducing the operating cost of the incubator, forming an organic incubation network, sharing basic incubation resources and ultimately improvement the incubating-efficiency.

1) Optimize the supporting way of the incubator to improve the incubating-efficiency from the perspective of reducing the management cost of incubator.

2) Optimize the allocation of resources to improve the incubating-efficiency from the perspective of avoiding re-construction of the same type of incubator, reducing waste of incubation resources during the allocation process and developing entrepreneurial financial services.

3) To optimize the N.E. review criteria, from providing targeted services and configuring to develop the need for resources to develop the incubating-efficiency.

In conclusion, the key to improving the incubation efficiency lies in the analysis of the business process of the incubator. It is important to distinguish between basic incubation resources and professional incubation resources, then provide targeted configuration services. That's a new requirement for the incubator industry. On the one hand, the government needs to change the thinking of the incubator industry construction planning, strengthen the construction of 
business environment, change from financial support to policy guidance, and build public incubation resource platform in the form of virtual incubator, or through self-built or entrusted. On the other hand, the incubator should become the main body of the entrepreneurial network, strengthen the profit consciousness of the organization instead of being a subordinate of an organization or industry, and actively participate in the market competition. At the same time, by providing personal customization and professional resources to promote the growth of N.E., the stripping out basic universal services to reduce the cost of running, and thereby raising the incubating-efficiency of the incubator. Finally. N.E. should take the initiative to connect with the market at the incubation phase and choose incubators based on the concentration degree of the incubation resource and the industrial docking service capacity, further optimize the resource allocation of the entire region and improve the incubation efficiency.

\section{Conflicts of Interest}

The author declares no conflicts of interest regarding the publication of this paper.

\section{References}

[1] OECD (2017) The Employees of New Emprises of OECD Members. https://data.oecd.org/entrepreneur/employees-by-business-size.htm

[2] Smilor, R.W. (1987) Commercializing Technology through New Business Incubators. Research Management, 30, 36-41. https://doi.org/10.1080/00345334.1987.11757061

[3] Smilor, R.W. (1997) Managing the Incubator System: Critical Success Factors to Accelerate New Company Development. IEEE Transactions on Engineering Management, EM-34, 146-155. https://doi.org/10.1109/TEM.1987.6498875

[4] Huang, M.H. and Huang, Y. (2001) An Analysis on Economics Theory Foundation of the Business Incubator's Forming and Developing. Science \& Technology Progress and Policy, 18, 1-4.

[5] Wang, S.Y. (2009) Research on the Theory and Practice of Scientific and Technological Enterprise Incubator. Nanjing University of Science and Technology.

[6] Zhang, Y.L. (2010) Review of Classic Literature on Entrepreneurship Research. Nankai University Press, Tianjing.

[7] Wang, J. (2012) Evaluation on the Technical Efficiency of the Business Incubators. Dalian University of Technology, Dalian.

[8] Kvale, S. (1997) InterViews: An Introduction to Qualitative Research Interviewing. Evaluation and Program Planning, 20, 287-288. https://doi.org/10.1016/S0149-7189(97)89858-8 


\section{Appendix I}

The list of DMUs, that are samples in Zhejiang, China

1) Ningbo Yinzhou Yinchuang Entrepreneurship Park Management Services Ltd.

2) Zhejiang University Science Park Ningbo Development Ltd.

3) Ningbo Yinchuang Technology Incubator Management Services Ltd.

4) NNUSP Venture Park

5) Hangzhou LefuZhihui Park Incubator Co., Ltd.

6) Hangzhou Dongbu Software Park Ltd.

7) Zhejiang Yinjiang Incubator Ltd.

8) Hangzhou Science and Technology Industrial Park Technology Innovation Service Center

9) Hangzhou Yuhang Hi-tech Industrial Park Incubator Ltd.

10) Bee-Hive in The Dream Town

11)The 7 th Space

12)Jiaxing Technology Innovation Service Center

13)Zhejiang XiuzhouHuigu Technology Innovation Center

14)Jinhua Science Park Innovation Service Center Ltd.

15)Wenzhou Hi-tech Industrial Park Innovation Center

\section{Appendix II}

\section{In-depth Interview of Incubating-efficiency Study}

(Semi-Structured)

What you will be doing today is an in-depth interview about the incubator efficiency. The interview time will be controlled at 60 minutes, and the interview will be conducted in a semi-structured form. You can expand on the basis of the problem or provide materials that you think are necessary, or you can elaborate on a problem.

\section{Part I}

The Summary of Interviewee

Document Code Name Position

Data Unit Local

\section{Part II}

Q1, Which field do you know about incubators? (Multiple-choice)

$\square$ 1) BIG DATA $\square$ 2) NEW METERIAL $\square$ 3) CURTURAL INNOVATION

$\square$ 4) MEDIA ADVERTISING $\square$ 5) EDUCATION $\square$ 6) GREAT HEALTH

$\square$ 7) BIO-MEDICINE $\square$ 8) SMART HOME

$\square$ 9) PHOTOELECTRIC COMMUNICATION

$\square$ 10) TECHNOLOGY FIELD (NON-SPECIFIC DIRECTION OF HIGHTECH ENTERPRISES)

$\square$ 11) OTHERS

Q2, What kinds do you know about incubators? (Multiple-choice)

๑) COMPREHENSIVE TYPE 


\section{$\square$ 2) PROFESSINAL TYPE I}

(With industry background, industry characteristics; An industry or enterprise attached;)

\section{$\square$ 3) PROFESSINAL TYPE II}

(It is positioned in the professional field, but it does not belong to any industry or enterprise subsidiary)

$\square$ 4) BASE TYPE(Provide normal services, such as policy, venue, funds, agents, personnel, etc.)

\section{口 5) SUPPORT TYPE}

(Regular service and high order service, such as professional legal affairs, market, industry docking.)

$\square$ 6) INVESTMENT TYPE(Focus on the investment and financing, equity, debt, IPO after B round of N.E.)

$\square 7)$ Others

Q3, What is your background, work experience or field of expertise? (Multiple-choice)

$\square$ 1) Teaching staff or researchers in the field of entrepreneurship

$\square$ 2) Relevant academic background in entrepreneurship field

$\square 3)$ Relevant working experience or entrepreneurial experience

$\square$ 4) Have experience in incubator

$\square$ 5) The professional manager of the incubator or the supervisor of the incubator

$\square$ 6) Others

Q4, What are the main strategic goals of the incubator you know? (Multiple-choice)

$\square$ 1) Perfecting the reginal industrial structure

$\square$ 2) Improve the regional innovation ability

$\square 3$ ) Increase employment in the region and balance the talent structure

$\square$ 4) To promote regional technological development

$\square$ 5) To assist in the transformation of the industry and the enterprise.

(The incubator is usually attached to a certain association or enterprise)

$\square 6)$ Improve the investment and financing environment in the region

$\square$ 7) Others

Q5, What is the main income for the incubator you know?(Multiple-choice)

$\square$ 1) The government subsidies(Include the government's bonus)

$\square$ 2) Other public sector subsidies(Funds that include associations or professional departments)

$\square$ 3) Place rentals (including property and equipment lease)

$\square$ 4) Training services (including entrepreneurship activities and competitions)

$\square$ 5) Technical service support (patent conversion, talent introduction, patent or trademark authorization)

$\square$ 6) Basic services (relevant license agency, HR service) 


\section{$\square$ 7) Business support services}

(legal assistance, trademark patent application, industry chain docking, policy award application)

$\square$ 8) Financial services ( $M$ \& A, investment and financing, loans, VC, IPO, etc.)

$\square$ 9) Selection, evaluation, filing, registration, exit counseling and other specific project application service

$\square$ 10) Other value-added service income

Q6, Sorted by the incubator to obtain the incubation resources (or build the incubation process system)?

(Please fill in the numbers 1 - 12)

_A Get professional talent resources from the government;

_B Access to professional talent resources from industry associations or other social organizations;

_C Receive special support funds from the government;

_D Receive special funds from industry associations or other social organizations;

_E Access to VC or funds from social institutions or financial markets;

_F Get the latest policy information or policy support from the government;

_G Get the latest policy information and policy support from industry associations or other social organizations;

_H Information or channels for obtaining patent or special technology from the government;

_I Obtain patent or technical information or access channels from associations or other social organizations;

_J Obtain financial service resources such as investment, financing, IPO;

_K Obtain professional qualifications or industry specific evaluation service resources;

_L Ability to obtain channel resources such as brand promotion, market access and industrial support;

\section{Part III}

Q7, Please provide an overview of your incubator (or your known incubator) and including new business situations?

Q8, What do you think is the biggest advantage or feature of your incubator? Where is compared with other incubators in the advantages and disadvantages?

Q9, How many times does the incubator carry out the activities for entrepreneurial each year? And each activity interval?

Q10, Is it necessary for the incubator to provide consulting and interpretation services for entrepreneurial policies ? Or can develop a profitable project for an incubator and provide, or can

Provide agency service for N.E. to get the external resources? Which mode is more efficient to incubators?

Q11, If the financial, personnel, strategy and other aspects of consulting ser- 
vices for new companies, will increase the speed of N.E. growth? Will the development of these services affect the overall incubation efficiency of the incubator (such as the ratio of inputs to outputs)?

Q12, What is the incubation resource that the N.E. most wants to acquire (or what resources does the incubator most want to invest in)?

Q13, Do you think that the incubator's funding sources are different, will it affect the development speed of N.E.(or the incubator's own property rights will affect the efficiency of incubation)?

Q14, N.E. is satisfaction with existing incubation services (compared to their peers)?

Q15, What is the scope of per capita service for incubator staff?

Q16, Will entrepreneurial instructors directly intervene in the operations of new businesses? (How to conduct entrepreneurial guidance)

Q17, What is the main business process? Is it necessary to simplify existing business processes or what needs to be improved?

Q18, What is the average period for new companies to get investment? What is the average investment amount?

Q19, What is the proportion of external venture capital funds in the investment obtained?

Q20, Will the incubator invest in N.E. with its own funds? If so, what is the weight?

Q21, Is there a perfect selection, review, agency, exit mechanism and related business guidance services?

Q22, If possible, are you willing to exchange with other incubators on various types of incubation resources to form a hierarchical network of incubator alliances?

At the moment, we have done a good job of today's interview. Thank you for your cooperation! 